\title{
Müller Glia in Retinal Development: From Specification to Circuit Integration
}

\author{
Joshua M. Tworig ${ }^{1 *}$ and Marla B. Feller ${ }^{1,2}$ \\ ${ }^{1}$ Department of Molecular and Cell Biology, University of California, Berkeley, Berkeley, CA, United States, ${ }^{2}$ Helen Wills \\ Neuroscience Institute, University of California, Berkeley, Berkeley, CA, United States
}

Müller glia of the retina share many features with astroglia located throughout the brain including maintenance of homeostasis, modulation of neurotransmitter spillover, and robust response to injury. Here we present the molecular factors and signaling events that govern Müller glial specification, patterning, and differentiation. Next, we discuss the various roles of Müller glia in retinal development, which include maintaining retinal organization and integrity as well as promoting neuronal survival, synaptogenesis, and phagocytosis of debris. Finally, we review the mechanisms by which Müller glia integrate into retinal circuits and actively participate in neuronal signaling during development.

Keywords: morphogenesis, neuronal-glial signaling, synaptogenesis, transcription factor, Notch

\section{OPEN ACCESS}

Edited by:

Edward S. Ruthazer,

McGill University, Canada

Reviewed by:

Yi-Rong Peng,

University of California, Los Angeles,

United States

Tudor Constantin Badea,

Transilvania University of Braşov,

Romania

*Correspondence:

Joshua M. Tworig

jtworig@berkeley.edu

Received: 16 November 2021 Accepted: 23 December 2021

Published: 04 February 2022

Citation:

Tworig JM and Feller MB (2022) Müller Glia in Retinal Development:

From Specification to Circuit

Integration

Front. Neural Circuits 15:815923.

doi: 10.3389/fncir.2021.815923

\section{INTRODUCTION}

Müller glia are the predominant synaptic astroglia of the retina. They tile the entire tangential retinal plane and exhibit a radial morphology which traverses from photoreceptors to inner limiting membrane. Müller glia exhibit a strikingly complex morphology, with distinct membrane specializations that contact photoreceptor outer segments, neuronal somata within nuclear layers, neurites within synaptic layers, and blood vessels throughout the retina. Their proximity to virtually every retinal cell type positions Müller glia ideally to guide the wiring and functioning of retinal circuits (Reichenbach and Bringmann, 2013).

Since the days of Heinrich Müller and Santiago Ramon y Cajal, who, respectively, discovered and later meticulously described the morphology of Müller glia and other astroglial cells (Müller, 1851; Ramon y Cajal, 1893), advances in genetic targeting as well as optical imaging have revealed essential roles for these cells in brain development and function. Müller glia, like other astroglial cell types, are born from the same neuroepithelial progenitors as those which produce neurons (Cepko et al., 1996). Müller glia are the only glial cell type to be born from progenitors within the retina. The two other retinal glial populations, astrocytes and microglia, migrate into the developing retina from other sources and play important developmental roles that are both distinct from and overlapping with those of Müller glia, as has been recently reviewed by other authors (Li et al., 2019; Dixon et al., 2021; Paisley and Kay, 2021).

Shortly following their birth, Müller glia begin to sculpt and integrate with nascent circuits as their morphological complexity grows and as they release molecules that are critical for neuronal survival and synaptogenesis (Reichenbach and Bringmann, 2013). As circuits mature in the retina and elsewhere in the brain, astroglia dynamically interact with neuronal processes and synapses via direct physical contact and signaling through an array of neurotransmitter receptors, ion channels, 
transporters, and exchangers expressed by glia (Lavialle et al., 2011; Rosa et al., 2015; Zhang et al., 2019). This enables Müller glia and other synaptic glial cells to integrate and respond to neuronal signaling across a range of time scales, often involving intracellular mobilization of second messengers such as calcium, as well as changes in gene expression and morphology (Uckermann et al., 2004; Rillich et al., 2009; Hasel et al., 2017).

Much effort has been focused on understanding the developmental trajectory and functions of astrocytes within brain circuits (Allen and Lyons, 2018), while less is known about the role of Müller glia in retinal circuit development. Here, we provide an overview of the current understanding of Müller glial development. We begin by describing the signaling events underlying Müller glial specification, patterning, and differentiation, and we move on to discuss their known roles in promoting retinal neuronal survival, synaptogenesis, and synapse pruning. Finally, we review the mechanisms by which Müller glia integrate into developing circuits, enabling them to rapidly respond to synaptic activity within the first few days after their exit from the cell cycle. We also note that although many recent studies have indicated a role for Müller glia in retinal regeneration by reprogramming gene expression (Goldman, 2014; Blackshaw and Sanes, 2021; Too and Simunovic, 2021) this will not be a focus of the present review.

\section{DEVELOPMENT OF MÜLLER GLIAL CELLS}

\section{Fate Determination and Differentiation}

Before Müller glial fate is specified among progenitor cells, the vertebrate retina has already completed much of its anatomical development; neuronal fate specification is complete, the cellular and plexiform layers have formed, and synapses are undergoing active refinement at this time. During vertebrate embryogenesis, the developing retina consists of a pool of mitotic, multipotent progenitor cells which arise from the neuroepithelium and eventually produce all classes of retinal neurons and Müller glial cells (Figure 1). These cell classes are specified in an orderly but overlapping sequence which is generally conserved across vertebrate species; ganglion cells are born first during late embryogenesis, followed by amacrine cells, horizontal cells, and cone photoreceptors. Rod photoreceptors differentiate over an extended period of time through the first postnatal days in mice, followed shortly thereafter by bipolar cells and Müller glia (Young, 1985; La Vail et al., 1991; Prada et al., 1991; Cepko et al., 1996; Wong and Rapaport, 2009).

These cell fate determinations are coordinated by transcriptional regulatory networks which generate distinct competence states wherein progenitor cells may produce a subset of postmitotic retinal cells (Figure 2). A long history of study using lineage tracing and genetic perturbation has implicated a number of transcription factors required for the maintenance of various progenitor competence states, including Pax6 (required for maintenance of multipotency), Sufu (a negative regulator of hedgehog signaling-induced gene expression), and Sox2 (downstream of hedgehog signaling and required for neurogenesis) (Bassett and Wallace, 2012). Additionally, the conserved transcription factor Ikaros confers competence among progenitors to produce early-born neuronal types, and its downregulation is required for transition into a competence state in which Müller glia are produced (Elliott et al., 2008). Conversely, upregulation of the homeobox gene Rax induces competence among late progenitors to produce Müller glia (Furukawa et al., 2000).

\section{Extrinsic Factors Affecting Müller Glial Development}

Within these competence states, cell extrinsic signaling regulates fate choice via contact-mediated signaling or release of soluble factors from neighboring cells (Livesey and Cepko, 2001; Bassett and Wallace, 2012; Cepko, 2014) (Figure 2). In particular, the Delta-Notch transmembrane signaling pathway is instructive for cell fate choice throughout development of the retina and the rest of the brain (Jadhav et al., 2006; Louvi and ArtavanisTsakonas, 2006). Several studies across multiple vertebrate species have shown that activation of Notch in late retinal progenitors promotes expression of Müller glial markers, in some cases at the expense of differentiated neurons (Henrique et al., 1997; Zheng-Zheng and Cepko, 1997; Furukawa et al., 2000; Scheer et al., 2001). This occurs via interactions between the Notch pathway and a variety of gene regulatory networks which include the transcription factors Lhx2, Sox9, and the basic helix-loop-helix (bHLH) superfamily. First, Lhx2 directly activates genes in the Notch pathway to induce proliferation among gliocompetent retinal progenitors. Lhx 2 remains highly expressed in glial precursors and is required for their terminal differentiation and expression of Müller glia-specific markers including $\mathrm{p} 27^{\text {Kip } 1}$, glutamine synthetase, and Sox9 (Melo et al., 2016a,b). Subsequently, Sox9 functions in late progenitors either to induce a gliocompetent state or to promote terminal differentiation into Müller glia (Kohn et al., 2015; Poché et al., 2008). Finally, a network of bHLH factors including Hes1, Hes5, and Hesr2 positively regulate Müller glial fate choice downstream of Notch activation by dimerizing and binding to regulatory elements of proglial genes (Furukawa et al., 2000; Hojo et al., 2000; Satow et al., 2001). These function in concert with non-DNA binding bHLH factors known as Inhibitor of differentiation 1-3 (Id1-3), which promote cell cycle progression among Müller glial progenitors by heterodimerizing with and sequestering proneuronal bHLH factors, thereby preventing their binding to DNA (Lasorella et al., 2002; Uribe and Gross, 2010; Mizeracka et al., 2013). Thus, the bHLH pathways interact with and modulate each other to coordinate Müller glial cell fate determination downstream of Notch activation.

In addition to contact-mediated signaling through Notch, several growth factor signaling pathways have been shown to promote Müller glial fate (Figure 2). These include ciliary neurotrophic factor (CNTF) and leukemia inhibitory factor (LIF), which promote Müller glial genesis by activating the Janus kinase (JAK)-signal transducer and activation of transcription (STAT) and extracellular signal-regulated kinase (ERK) pathways 


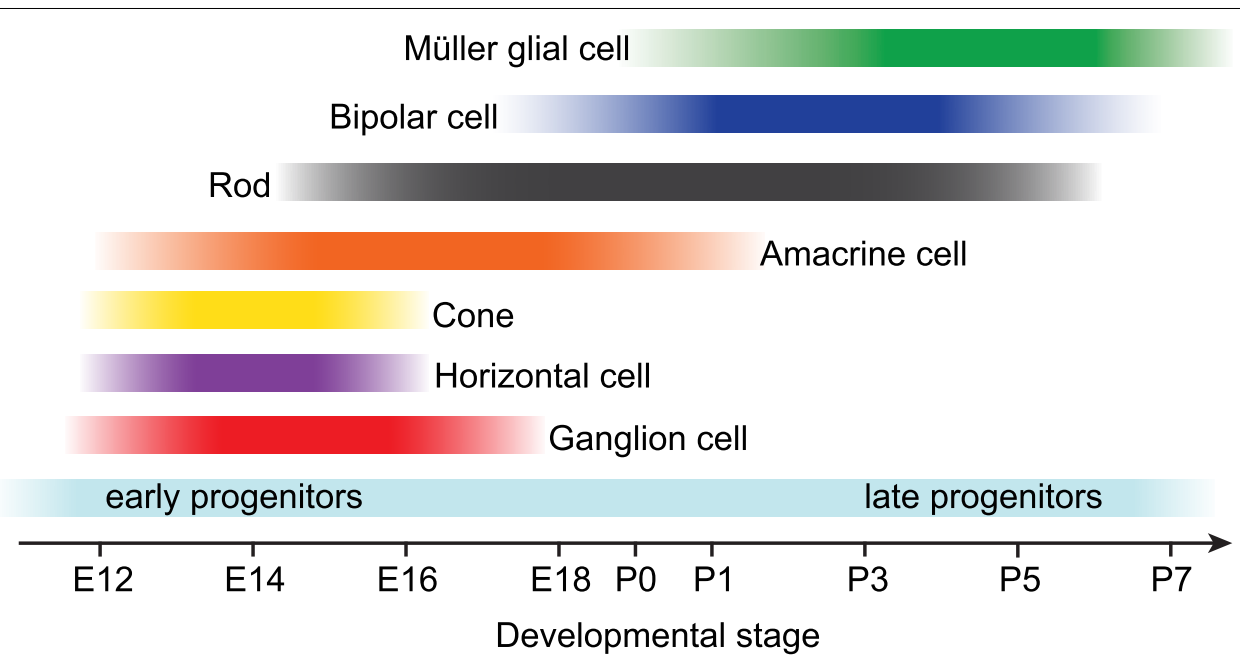

FIGURE 1 | Developmental timeline of retinal neuroepithelium-derived cell birth in rodents. Near the end of embryonic development (starting around E12 in rodents), multipotent progenitor cells become competent to produce all retinal neurons and Müller glia in a conserved, overlapping temporal sequence. Early retinal progenitors first produce ganglion cells, horizontal cells, cone photoreceptors, and most amacrine cells prior to birth. Postnatally, late retinal progenitors produce most rod photoreceptors, bipolar cells, and lastly Müller glia. Adapted from Bassett and Wallace (2012).

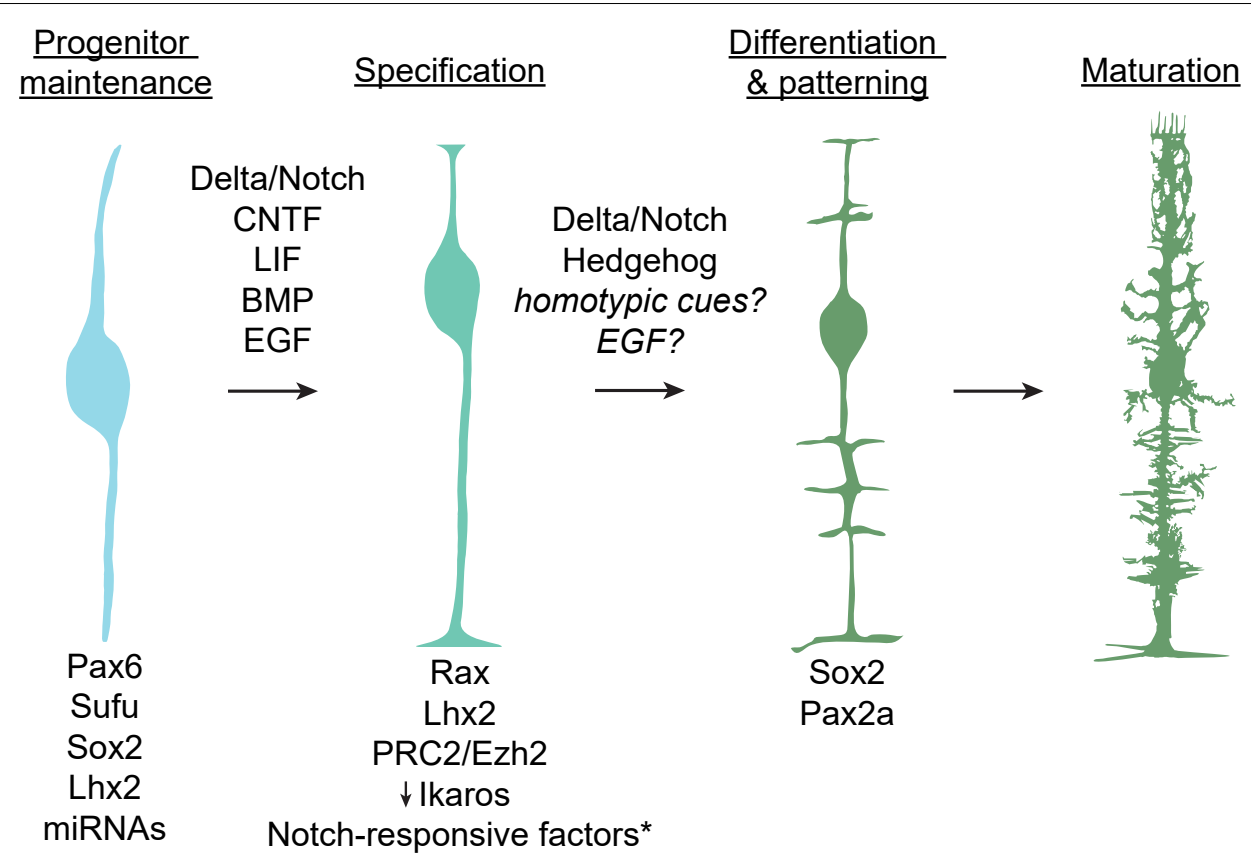

FIGURE 2 | Known factors underlying the progression from retinal progenitors to mature Müller glia. Cell intrinsic molecules including transcription factors and microRNAs which mediate maintenance of cell identity or differentiation at each step are listed at bottom. Contact-dependent (Delta/Notch) and growth factor signaling pathways thought to promote Müller glial specification and differentiation are listed above arrows. *Notch-responsive factors include Hes1, Hes5, Hesr2, Id1-3, Sox9, and Nfia/b/x.

involved in cell growth and proliferation (Goureau et al., 2004; Todd et al., 2016). Transient expression of bone morphogenetic protein (BMP) near the end of retinal neurogenesis leads to phosphorylation of Smad1/5/8 in prospective Müller glial cells, leading to upregulation of Müller glia-specific genes (Ueki et al., 2015). Similarly, epidermal growth factor (EGF) promotes Müller glial fate using a mechanism that interacts with BMP signaling, and progenitor competence to produce Müller glia in response to EGF begins around P0 in rodents (Lillien, 1995; Lillien and Wancio, 1998; Close et al., 2006; Ueki and Reh, 2013). On the other hand, transforming growth factor $\beta$ (TGF $\beta$ ) secreted from neurons inhibits proliferation of Müller glial precursors in a manner that is antagonistic with EGF signaling (Close et al., 2005). This occurs via activation of the cyclin-dependent kinase 
inhibitor $\mathrm{p} 27^{\text {Kip } 1}$, which is required for cell cycle withdrawal in Müller glial precursors (Levine et al., 2000).

Despite the progress made toward defining the regulatory networks underpinning Müller glial fate determination, this is still a poorly understood process. Gain- and loss-of function studies have identified a variety of pro-glial and pro-neuronal bHLH transcriptional regulators under the control of Notch. However, the effects of Notch signaling are highly pleiotropic, resulting in a range of activities that either repress or promote progenitor differentiation depending on developmental timepoint, cell type, and transcriptional cross-talk with other signaling pathways such as JAK-STAT (Louvi and ArtavanisTsakonas, 2006). Although this complicates our understanding of Müller glial differentiation, advances in single cell RNA profiling enable pseudo-tracking of transcriptomes among all neural cell types across development. This methodology is currently being used to discover novel regulators of cell fate using differential expression analysis (Shekhar and Sanes, 2021). For example, a recent study using single-cell RNA-sequencing revealed that the Notch-regulated nuclear factor 1 (NF1) transcription factors $\mathrm{Nfia} / \mathrm{b} / \mathrm{x}$ are enriched in late retinal progenitors and promote the formation of Müller glia and bipolar cells (Clark et al., 2019).

\section{Roles of Epigenetics and miRNAs in Müller Glial Development}

Transcriptional regulatory networks function in an environment in which chromatin varies in its accessibility depending on covalent modifications to histones or DNA. Recent studies using epigenomic tools such as ChIP-Seq have pointed toward histone modification as a mechanism of Müller glial specification and differentiation. Polychrome repressive complex 2 (PRC2) acts as a repressor of gene expression by transferring methyl groups to lysine 27 on histone 3 (H3K27me2/3) (Hansen et al., 2008). Inactivation of the histone methyltransferase Ezh2, a component of PRC2, leads to enhanced and premature specification of Müller glia at the expense of late born neuronal types, possibly caused by downregulation of proneural factors. Ezh2 knockout retinas display enhanced expression of markers for mature Müller glia, along with glial membrane disorganization and upregulation of GFAP, suggesting that Ezh2 also functions as a regulator of differentiation in these cells (Iida et al., 2015; Zhang et al., 2015). RNA-sequencing reveals that the effects of Ezh2 are due in part to dysregulation of the Müller glia-promoting gene Hes1, which is normally targeted for $\mathrm{H} 3 \mathrm{~K} 27 \mathrm{me} 3$ modification by PRC2/Ezh2, thereby dampening glial differentiation under normal conditions (Ueno et al., 2017).

A series of studies has also implicated microRNAs (miRNAs) in regulating the timing of Müller glial specification or differentiation via translational silencing of various progenitor genes. Initial evidence in support of this hypothesis came from conditional knockout studies which abolished the function of the RNA processing enzyme Dicer, halting the maturation of miRNAs during retinal development. This resulted in agenesis of Müller glia associated with perturbed expression of Notchresponsive genes and loss of the pro-glial transcription factor Sox9, as well as defects in specification of some neuronal types (Georgi and Reh, 2010; Davis et al., 2011). RNA expression studies have identified specific miRNAs that are upregulated or downregulated during retinal progenitor differentiation. Microarray expression data across development along with targeted knock-down of miRNAs were used to identify three targets of Dicer - let-7, miR-125, and miR-9 - as key factors in the specification of late progenitors which go on to produce Müller glia (La Torre et al., 2013). Another example is the highly conserved miR-7a, which directly binds Notch3 mRNA and suppresses its expression. This prevents differentiation of retinal progenitors into Müller glia, as evidenced by perturbed expression of the glial markers glutamine synthetase and cyclin D3 following miR-7a misexpression. This occurs without interfering with specification or proliferation of other cell types, suggesting that in the retina, the miR-7a/Notch3 system functions primarily in Müller glia differentiation (Baba et al., 2015). For a comprehensive review of the known miRNAs affecting Müller glial specification or differentiation, see Quintero and Lamas (2018).

Further study aimed at unraveling the interactions between Müller glial epigenome and transcriptome during differentiation, along with expanded access to new sequencing methods and the data they produce will provide necessary detail in our understanding of Müller glial specification and differentiation.

\section{Müller Glial Patterning and Morphogenesis}

By the time of Müller glial differentiation, around postnatal day 5 (P5) in mice, anatomical development of the retina is nearly complete, with most neuronal types already present across three nuclear layers and two nascent synaptic layers (Hoon et al., 2014). Components of the Notch signaling pathway remain highly expressed in Müller glia for an extended period following cell cycle exit, and are required for maintenance of Müller glial identity during this time (Nelson et al., 2011). Initially, Müller glia closely resemble retinal progenitor cells, with simple apical and basal processes projecting from the cell body, which is located near the middle of the inner nuclear layer (INL) following interkinetic nuclear migration from the apical region (MacDonald et al., 2015) (Figure 2). Müller glia are uniformly distributed across the retina (Figure $\mathbf{3 A}$ ), and the spatial organization of their cell bodies within the INL is random, seemingly only constrained by physical restrictions from nearby cells (Figures 3B,C) (Wang et al., 2017). This stands in contrast to some retinal neurons like horizontal cells and starburst amacrine cells, which form mosaics of regularly spaced cell bodies (Reese and Keeley, 2015; Keeley et al., 2020).

Despite the random arrangement of Müller glial cell bodies within the INL, their apical and basal processes, which project through the outer and inner plexiform layers (OPL/IPL), outer nuclear layer (ONL), and outer/inner limiting membranes (OLM/ILM), are arranged in a semi-regular array within the tangential retinal plane (Franze et al., 2007). Müller glia are generally regarded as a homogeneous cell type in mice and primates based on gene expression analysis (Shekhar et al., 2016; Wang et al., 2017; Peng et al., 2019; Yan et al., 2020). In developing chicken retina, however, Müller glia comprise multiple clusters 
A

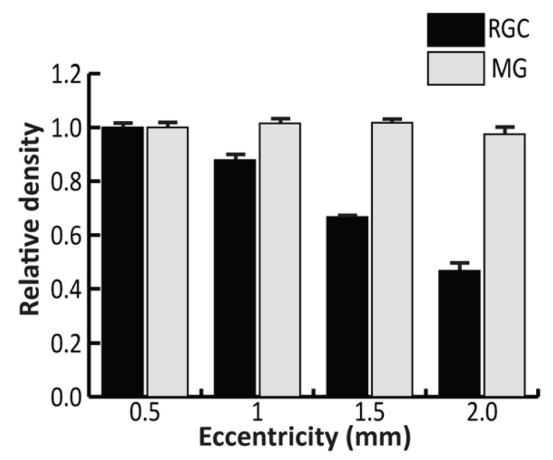

D

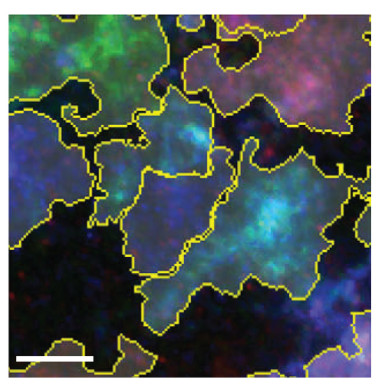

B

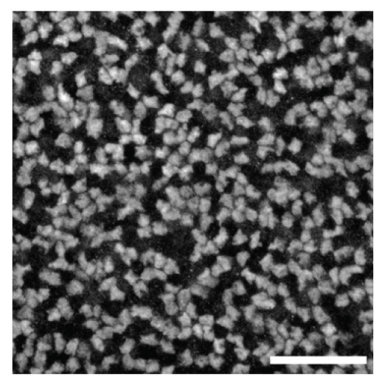

E

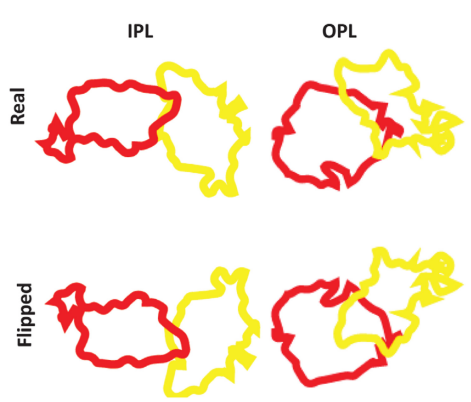

C

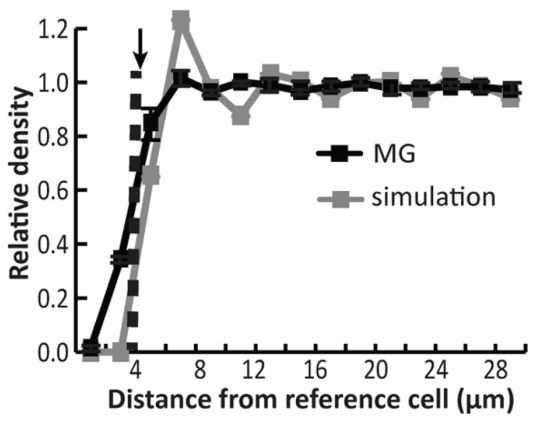

$\mathbf{F}$

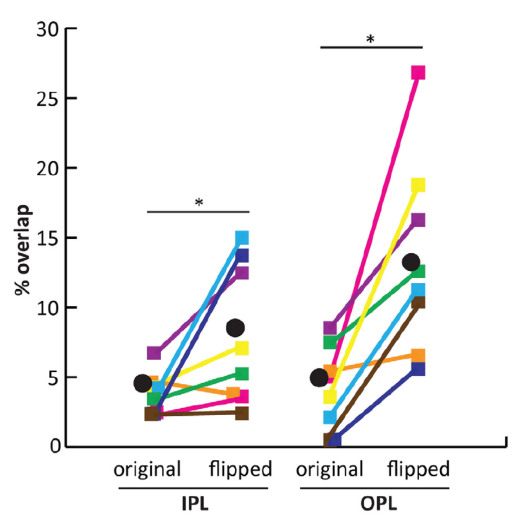

FIGURE 3 | Müller glial (MG) cell bodies are uniformly distributed across the mouse retina and randomly arranged in the tangential plane, while processes in synaptic layers tile the retina with minimal overlap. (A) In contrast to retinal ganglion cells, MG are uniformly distributed across all retinal eccentricities. (B) Staining for the glial marker Sox9 in the inner nuclear layer (INL) reveals tight packing of cell bodies separated by small gaps. (C) Density recovery profile (DRP) for MG cell bodies (black) reveals an exclusion zone which matches the average cell body size. DRP for simulated random arrays (gray) matched in cell size and density to MG corresponds well with the true MG DRP, suggesting random assortment of cell bodies in the INL. (D) Combinatorial expression of multiple fluorescent markers via the Brainbow system followed by contiguous spatial segmentation delineates the territories of individual cells within the inner and outer plexiform layers (IPL/OPL). (E) Arbor overlap between neighboring pairs of MG was calculated before and after flipping each image about its horizontal axis. (F) Arbor overlap is significantly greater when territories are flipped, suggesting non-random arrangement. Scale bars (in $\mu \mathrm{m})$ : 50 (B), 5 (D). Adapted from Wang et al. (2017).

defined by retinal position-dependent expression of various markers, some of which follow a progressive developmental restriction to either central or peripheral retina (Yamagata et al., 2021). The regular spacing of Müller glial stalks seems to be governed by homotypic interactions between their processes which begin extending laterally into synaptic layers around P6 in the mouse. Using the 'Brainbow' approach to stochastically label neighboring Müller glia with different colored fluorescent reporters, it was found that Müller glial lateral processes tile across the OPL and IPL, with minimal overlap between arbors of neighboring cells (Wang et al., 2017) (Figures 3D-F). The hypothesis that homotypic repulsive interactions between Müller glial processes enable regular tiling is supported by laser ablation experiments in which individual Müller glial cells were removed from the embryonic zebrafish retina, resulting in a region of OPL devoid of glial processes. This region was subsequently filled in by neighboring intact Müller glial processes, suggesting a temporary relief of glia-glia interactions that normally prevent process overlap between neighbors (Williams et al., 2010).

Molecules mediating homotypic interactions between Müller glia have not yet been identified. Among astrocytes of the
Drosophila ventral nerve cord, tiling, infiltration of neuropil, and domain size are controlled by fibroblast growth factor (FGF) secretion from neurons and subsequent signaling through the astrocytic FGF receptor Heartless (Htl) (Stork et al., 2014). The cell adhesion molecule Lapsyn acts downstream of or in parallel with FGF signaling to control astrocytic branch morphogenesis (Richier et al., 2017). In mouse cortical astrocytes, the cell adhesion molecule hepaCAM plays a similar role in branch outgrowth, in part by stabilizing connexin $43(\mathrm{Cx} 43)$ to promote astrocytic coupling (Baldwin et al., 2021). Whether these factors influence Müller glial tiling is not known but represent interesting avenues of future research.

As Müller glia mature, they undergo dramatic morphological change across the retina: basal processes form branching endfeet which ensheathe neuronal somata in the ganglion cell layer (GCL); fine lateral processes ramify throughout the synaptic layers; apical processes wrap around photoreceptor cell bodies in the ONL and project finger-like microvilli through the OLM to contact photoreceptor outer segments; and processes extend throughout the retina to specifically contact blood vessels and mediate neurovascular coupling (Figures 4A,B). Within the 


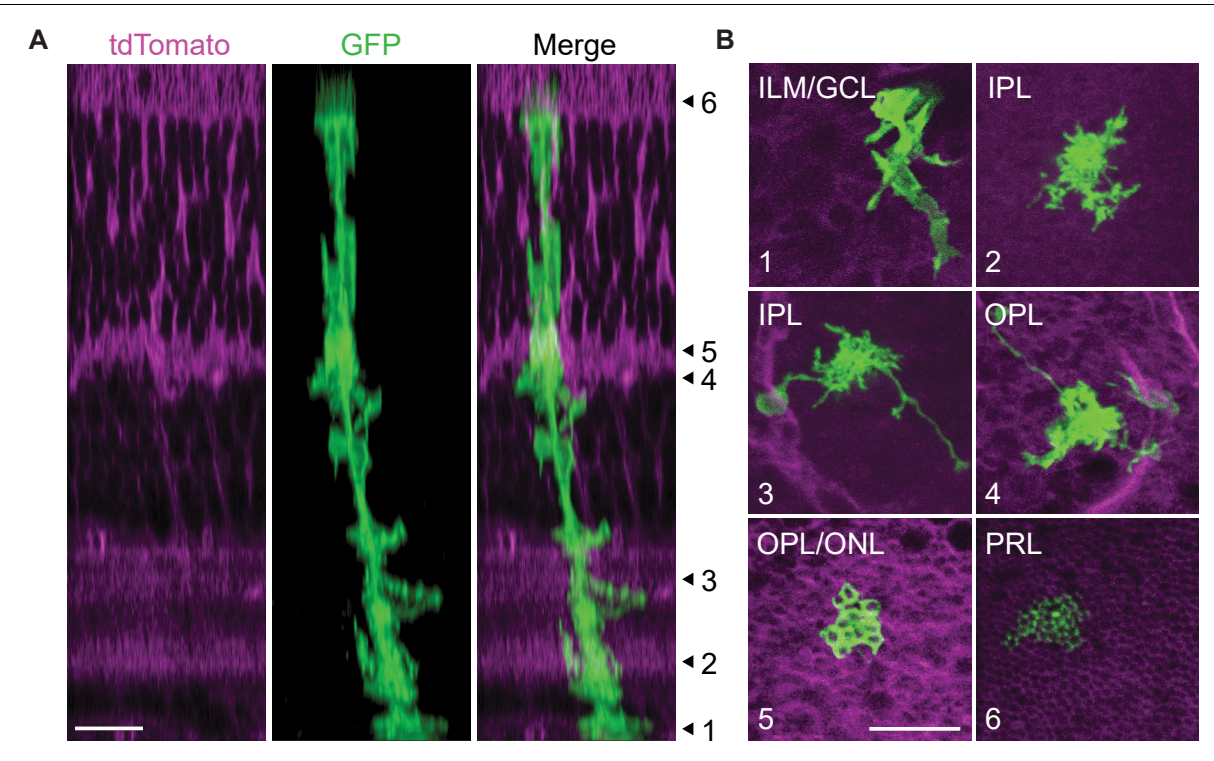

FIGURE 4 | Morphological compartments of mature Müller glia. (A) Orthogonal projection of a 2-photon volumetric image from mature GLAST/mTmG mouse retina. This mouse line expresses membrane-bound tdTomato ubiquitously, and sparse activation of Cre recombinase induces expression of membrane-bound GFP in a subset of Müller glia. Numbered arrowheads correspond to focal planes shown in (B) to highlight different morphological compartments. (B) (1) Müller glial endfeet in the inner limiting membrane (ILM) and ganglion cell layer (GCL). (2) Lateral processes in the inner plexiform laer (IPL). (3) Lateral processes and long-ranging blood vessel-contacting processes in the IPL. (4) Lateral processes and blood vessel-contacting processes in the outer plexiform layer (OPL). (5) Photoreceptor terminal-ensheathing processes at the OPL-outer nuclear layer border. (6) Müller glial microvilli extending between photoreceptor inner segments. PRL: photoreceptor layer. Scale bars $10 \mu \mathrm{m}$. From Tworig, unpublished images.

IPL, lateral processes exhibit sublaminar-specific outgrowth, with denser ramification in sublayers $\mathrm{S} 1, \mathrm{~S} 3$, and S5 than in the choline acetyltransferase-positive $(\mathrm{ChAT}+)$ sublayers S2 and S4 (Reichenbach and Reichelt, 1986; Metea and Newman, 2006; Wang et al., 2017; Tworig et al., 2021).

The signaling mechanisms underlying outgrowth and spacing of Müller glial processes remain unknown, although hedgehog signaling originating from retinal ganglion cells may play a role in setting up their orientation (Wang et al., 2002). In addition to its previously mentioned role in glial specification, the hedgehogresponsive transcription factor Sox2 is required in Müller glia for maturation of their basal endfeet and lateral processes in synaptic layers (Bachleda et al., 2016). A possible mechanism for Sox2mediated morphogenesis which has yet to be explored implicates EGF receptor (EGFR) activity, which is directly upregulated by Sox2 (Hu et al., 2010) and overlaps with the period of Müller glial process outgrowth in rodents (Close et al., 2006; Wang et al., 2017). Chronic manipulations of EGF signaling have revealed its role in glial fate determination as previously described (Lillien, 1995; Lillien and Wancio, 1998; Ueki and Reh, 2013; Sardar Pasha et al., 2017), but EGFR activation also induces cytoskeletal rearrangements and membrane protrusions independent of transcriptional modulation (Xie et al., 1998). Exogenous EGF promotes migratory behavior of cultured Müller glial cells (Pena et al., 2018) and slightly enhances motility of Müller glial processes during development (Tworig et al., 2021), but further study is needed to determine whether endogenous EGFR signaling is instructive for glial process outgrowth during normal retinal development.
Due to the stereotyped nature of Müller glial morphogenesis across retinal layers, as well as the genetic and experimental tractability of the retina, the cellular and molecular events underlying process outgrowth are investigable using genetic screening and imaging approaches. This was recently done using a CRISPR-based reverse genetic screen, which identified 41 genes implicated in various aspects of Müller glia morphogenesis in zebrafish (Charlton-Perkins et al., 2019). These genes affected distinct morphological features of Müller glia, including cell body position (examples: Nav1b, Lamb4, and Timp2b), tiling across the tangential plane (Nav1b, F8, Icn2, and Cdhr1), and lateral outgrowth of processes within the IPL and OPL (Nav1b, Mapa1b, Fat1b, Egr1, Slitrk2, and Dcaf8). In general, genes that are upregulated early during Müller glial differentiation affect broad aspects of morphogenesis, while genes upregulated later have more restricted effects on individual aspects of morphology. Many of these genes are conserved among glia in other species. One example is Pax $2 a$, which is expressed by many glial cell types and is known to modulate cell morphology, adhesion, and differentiation (Charlton-Perkins et al., 2011). In zebrafish retina, Pax2a-mutant Müller glia display aberrant morphological characteristics in every retinal layer, including defects in tiling and outgrowth of processes into synaptic layers (Charlton-Perkins et al., 2019).

These studies of Müller glial morphogenesis in mouse and zebrafish were carried out by examining glial morphology in fixed samples. A better understanding of the factors involved in Müller glial process outgrowth and distribution will be achieved by carrying out live imaging of labeled Müller glia during 
retinal development. To this end, several studies have revealed that vertebrate Müller glia exhibit dynamic branching as they mature, with processes in synaptic layers undergoing extensions, retractions, sprouting, and elimination on the timescale of minutes as they sample space across the OPL and IPL (Williams et al., 2010; MacDonald et al., 2015; Tworig et al., 2021). This motility halts shortly after the onset of vision, suggesting that it is developmentally regulated or suppressed by synaptic activity. The potential roles for synaptic activity in Müller glial development are discussed in greater detail below.

\section{ROLES OF MÜLLER GLIA IN RETINAL DEVELOPMENT}

Throughout the developing central nervous system, astroglia broadly influence key events including neuronal growth and maturation, synapse formation and pruning, and critical period timing (Allen and Lyons, 2018; Ackerman et al., 2021; Ribot et al., 2021). Similarly, Müller glia affect many aspects of retinal development ranging from its overall cytological organization to the formation of specific visual circuits.

\section{Maintenance of Retinal Organization}

Müller glia are essential for the guidance and maintenance of cellular organization across the retina. This is evidenced by knockout studies in which retinas with perturbed Müller glial development exhibit lamination defects and form ectopic neural rosettes (Wang et al., 2002; Bachleda et al., 2016; Wohl et al., 2017). Disruption of Müller glial function with the glia-specific toxin $\alpha$-aminoadipic acid prior to photoreceptor maturation abolishes contacts between Müller glial microvilli and photoreceptors and leads to aberrant migration of photoreceptors toward the subretinal space (Rich et al., 1995). Absence of Müller glia during zebrafish development results in retinal disorganization characterized by a propensity for tearing and aberrant photoreceptor spacing, possibly due to a reduction in tensile strength normally provided by Müller glia during retinal maturation via expression of various ECM-interacting proteins such as integrins (Guidry et al., 2003; MacDonald et al., 2015; Nagashima et al., 2017) (Figures 5A,B). Strikingly, however, Randlett et al. (2013) found that gross laminar organization and synaptic structures are maintained in zebrafish retinas devoid of Müller glia following pharmacological interference of Notch signaling, suggesting that neurons are able to form a rudimentary neuropil and layered structure autonomously.

\section{Secretion of Neurotrophins}

As the retina matures, Müller glia secrete a variety of trophic factors that affect neuronal survival, promote neuritogenesis, or protect against excitotoxicity. This was initially determined by observing enhanced neuronal growth and neurite elongation among retinal neurons when cultured with Müller glia or Müller glia-conditioned media (Raju and Bennett, 1986; García et al., 2002). Subsequent study implementing Müller glianeuron co-culture has identified a panel of Müller glia-derived growth factors or cytokines that mediate survival (examples: pigment-epithelium derived factor/PEDF, vascular endothelial growth factor/VEGF) (Saint-Geniez et al., 2008; Bai et al., 2009; Unterlauft et al., 2014) or neurite outgrowth (CNTF, interleukin6/IL-6) (Yoshida et al., 2001) among retinal neurons. Co-culture experiments have also implicated glial ATP release as a promoter of neuritogenesis among RGCs via activation of $\mathrm{P}_{2} \mathrm{Y}_{6}$ receptors (Taguchi et al., 2016). Some of these signaling pathways work in concert with $\mathrm{Wnt} / \beta$-catenin signaling in Müller glia, which modulates secretion of known neurotrophins including CNTF and brain-derived neurotrophic factor (BDNF) (Patel et al., 2015; Musada et al., 2020).

Under certain experimental conditions, neuronal signaling has been shown to modulate Müller glial secretion of trophic factors. For instance, extracellular ATP can cause release of FGF from Müller glia downstream of glial P2Y receptors (Reichenbach and Bringmann, 2016), while glutamate enhances glial synthesis of a panel of neurotrophins including BDNF, glial-cell line derived neurotrophic factor (GDNF), and nerve growth factor (NGF) (Taylor et al., 2003). This is consistent with known roles of glial cells in preventing glutamate excitotoxicity. Furthermore, hypoxic regulation of VEGF release from Müller glia and astrocytes following neuronal activity is thought to promote retinal vascularization during development (Stone et al., 1995; Lange et al., 2012). Through another pathway independent of VEGF, Müller glia secrete the pro-angiogenic compound Norrin, which binds to Frizzled-4 receptors and Lrp 5 co-receptors on endothelial cells within microvasculature to activate $\mathrm{Wnt} / \beta$-catenin signaling, thereby promoting growth of intraretinal capillaries (Xu et al., 2004; Ye et al., 2009). Norrin also exhibits neuroprotective effects in the retina following excitotoxic damage and promotes dendritic development in cortical neurons following secretion from astrocytes (Seitz et al., 2010; Miller et al., 2019). Although Norrin is constitutively expressed in Müller glia, whether its secretion is modulated by neuronal activity is unknown. Interestingly, release of neurotrophins from Müller glia can be modulated by trophic factors released from activated microglia, but whether this is also a feature during development remains to be determined (Harada et al., 2002; Wang et al., 2011).

In recent years, studies aimed at identifying glia-derived trophic factors important during retinal development have shifted toward high-throughput approaches to screen the glial secretome for candidate molecules using liquid chromatography and/or mass-spectrometry, with subsequent testing of candidates for neurotrophic activity in cell culture or retinal explant. These studies have identified molecules including osteopontin, LIF, transferrin, basigin, clusterin, and C-X-C motif chemokine 10 (CXCL10) as neurotrophic factors that are secreted by Müller glia and exhibit neuroprotective effects on retinal neurons (Toerne et al., 2014; Ruzafa et al., 2018). Interpretation of these results is limited, however, due to loss of three-dimensional organization and known alterations in gene expression profiles of Müller glia upon dissociation and growth under culture conditions (Hauck et al., 2003; Wohl et al., 2016). Future experiments using ex vivo or intact retina in combination with targeted genetic manipulation of pathways of interest may confirm a role for these glia-derived candidate molecules in regulating retinal development. 
A

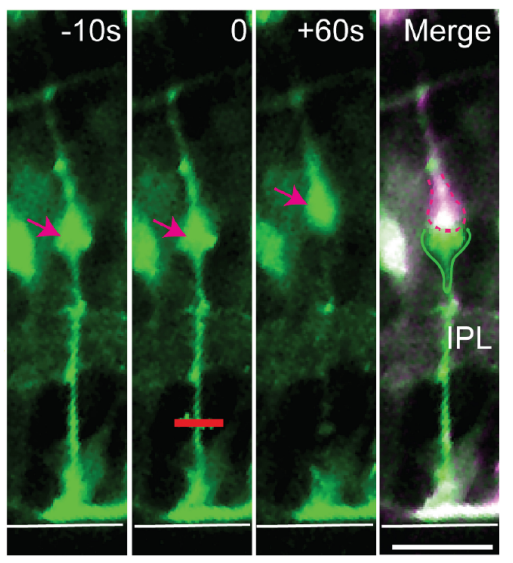

B

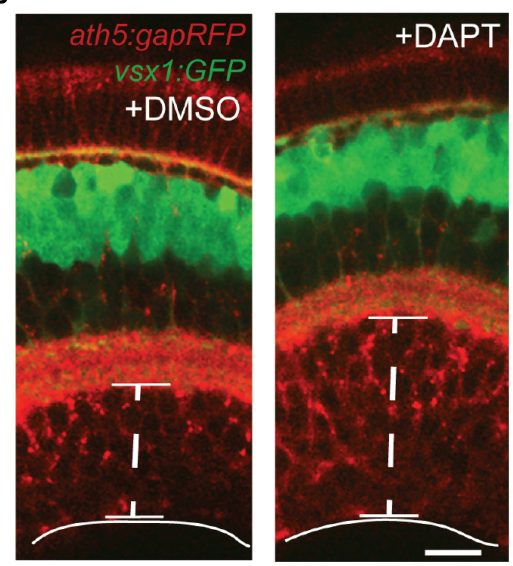

FIGURE 5 | Müller glia act as springs to maintain strength and integrity of the retina. (A) Laser ablation was used to sever the basal processes of GFAP:GFP Müller glia from zebrafish in vivo. After ablation at $t=0$ (red line), the basal process retracts and the cell body (arrow) is displaced apically, suggesting that Müller glia are under tension during development. (B) Retinal development in the absence of Müller glia following treatment with the Notch pathway inhibitor DAPT leads to expansion of the ganglion cell layer (GCL) without an increase in cell number, suggesting that tension along Müller glia promotes integrity of the GCL. Retinal neurons are labeled with membrane RFP using ath5:gapRFP, and bipolar cells are labeled with GFP using vsx1:GFP. Scale bars 15 $\mu \mathrm{m}$. Adapted from MacDonald et al. (2015).

\section{Promotion of Synapse Turnover}

Müller glia maturation occurs during a period of robust synaptogenesis, positioning them to influence the formation or stability of new synapses via secretion of various molecules. Thrombospondins (TSPs) are synaptogenic factors that are secreted by astroglia and interact with gabapentin receptors $(\alpha 2 \delta$ 1) on neurons (Eroglu et al., 2009). Müller glia express TSP1 and TSP2 with enrichment in the OPL and in specific sublayers of the IPL, and impaired secretion of TSPs during development disrupts synapse formation in both plexiform layers (Koh et al., 2018). Recent evidence indicates that TSP1 acts specifically on direction-selective ganglion cells (DSGCs) to promote excitatory synapse formation with their presynaptic partners, starburst amacrine cells (SACs), requiring both $\alpha 2 \delta-1$ receptor and $\beta 1$ integrin expression in DSGCs for this activity. The same study revealed that TSP1 knockout also reduces inhibitory synapse formation throughout the IPL, although perhaps compensatory and subsequent to loss of excitation (Koh et al., 2019). This is reminiscent of the mouse striatum, where signaling through astrocytic $\mathrm{GABA}_{B}$ receptors during synaptic activity leads to activation of the $G_{i}$ pathway and subsequent TSP1 secretion from astrocytes to promote synaptogenesis between corticostriatal axon terminals and medium spiny neuron dendritic spines (Nagai et al., 2019). Neuronal activity-evoked expression of glial TSPs and other synaptogenic cues possibly depends on glial calcium mobilization downstream of receptor activation (Tran and Neary, 2006; Farhy-Tselnicker et al., 2021). It will be interesting to find out whether a similar mechanism is at play in Müller glia, which undergo robust activity-evoked responses during retinal development as described further below (Rosa et al., 2015; Zhang et al., 2019).

There are likely other synaptogenic factors secreted by Müller glia that have yet to be characterized, given the large and growing list of astrocyte-secreted factors elsewhere in the brain (Tan et al., 2021). A number of these are expressed by Müller glia throughout development but have not been tested for a role in synaptogenesis. D-serine is a co-agonist of NMDA receptors, exhibits synaptogenic properties when released from astrocytes, and has been detected in developing and mature Müller glia along with serine racemase, the enzyme that produces D-serine (Schell et al., 1997; Williams et al., 2006; Diaz et al., 2007; Dun et al., 2008; Diniz et al., 2012). D-serine has also been reported to enhance expression of immediate early genes in Müller glia downstream of NMDA receptor activation and phosphorylation of cAMP response element binding protein (CREB) transcription factors, which are responsive to calcium and CAMP signaling (Lamas et al., 2007; Hasel et al., 2017). Modulation of glial gene expression following $\mathrm{D}$-serine-enhanced NMDAR activation occurs in part via cytosolic translocation of the calcium-binding transcriptional modulator DREAM (downstream regulatory element antagonist modulator) and a reduction in its DNA-binding ability (ChaviraSuárez et al., 2008). Further study is necessary to determine whether Müller glial D-serine release also acts as a direct synaptogenic cue during retinal development in vivo.

It is possible that Müller glia also secrete anti-synaptogenic compounds to facilitate synapse turnover. SPARC/osteonectin secreted from astrocytes inhibits excitatory synapse formation in neuron-glia co-culture and in superior colliculus between RGCs and their targets (Kucukdereli et al., 2011; Albrecht et al., 2012). SPARC is also expressed by Müller glia throughout their development and into adulthood, suggesting a role in modulating synaptic development (Vincent et al., 2008). This story is perhaps complicated by the recent detection in the Müller glial secretome of the pro-synaptogenic SPARC-like protein 1 (SPARCL1/Hevin), whose synaptogenic activity is antagonized by SPARC. For a more complete list of neurotrophic 
and synaptogenic molecules potentially secreted by Müller glia, see Musada et al. (2020).

The influence of Müller glia on synapse formation or maturation likely varies by retinal circuit, neuronal type, and developmental context. In the developing chick retina, asyet unidentified factors secreted by glia promote expression of $\mathrm{M}_{2}$ muscarinic acetylcholine receptors (mAChRs) on neurons, with minimal effect on expression of other mAChRs (Belmonte et al., 2000). In developing zebrafish OPL, although Müller glial lateral process elaboration and ensheathment of photoreceptor terminals overlap with the period of synaptogenesis, photoreceptor synapses develop normally and remain stable following laser ablation of Müller glial apical processes, suggesting that glial contact is dispensable for synaptogenesis in the outer retina (Williams et al., 2010). However, photoreceptor synapses were assessed in the context of localized ablation of a few Müller glial cells, and although this rules out a glial contact-dependent mechanism, a paracrine function for Müller glia in promoting synaptogenesis within the OPL is plausible. Consistent with this idea, Müller glial expression of the molecular scaffold harmonin during development is necessary for photoreceptor synaptic organization and function in zebrafish (Phillips et al., 2011). It is not yet known whether contact-dependent signaling from Müller glia contributes to synapse formation in the IPL.

Müller glia may also regulate neuronal development via phagocytosis of cellular debris including apoptotic cells and synapses. This has been shown using electron microscopy in developing chick retina which revealed electron-dense debris derived from degenerating cells (Hughes and Lavelle, 1975), as well as TUNEL staining in developing turtle and rat retina which revealed pyknotic bodies and cytoplasmic DNA within vimentin-positive glial processes (Egensperger et al., 1996; Francisco-Morcillo et al., 2004). This seems to occur in parallel with phagocytosis of cellular debris in developing retina by microglia (Marín-Teva et al., 1999). The mechanisms underlying recognition and phagocytosis of cellular debris by Müller glia during development are unknown, but in mature retina phagocytosis of photoreceptor debris after injury requires the phagocytic pathway components Rac1 GTPase and phosphatidylserine (Nomura-Komoike et al., 2020). Phagocytic activity among Müller glia during development may be mediated by the receptor tyrosine kinase Mertk, the loss of which leads to cell-autonomous morphological alterations in Müller glia and reduced synapse density in postnatal retina, as well as reduced synaptogenic potential among cultured Müller glia (Scott et al., 2001; Koh et al., 2018).

For a summary of the impacts of Müller glia on retinal development described above, see Figure 6A.

\section{INTEGRATION INTO CIRCUITS}

\section{Participation in Patterned Activity}

Müller glia are born and mature in an environment in which neural circuits are spontaneously active despite the absence of visual input. In many vertebrates, this activity is characterized by propagating waves of depolarization, termed retinal waves, which are critical for key aspects of visual system development such as eye-specific segregation and retinotopic refinement of retinogeniculate synapses (Blankenship and Feller, 2010; Arroyo and Feller, 2016; Kerschensteiner, 2016; Choi et al., 2021). Patterned spontaneous activity in the retina undergoes three distinct phases in mammals: stage 1 waves occur embryonically and are mediated by gap junctions and cholinergic signaling (Bansal et al., 2000), stage 2 waves are mediated by volume ACh release from SACs (Ford et al., 2012; Xu et al., 2016), and stage 3 waves are mediated by glutamate spillover from bipolar cells (Blankenship et al., 2009). In the days following their birth in mouse retina, Müller glia begin responding to cholinergic waves by undergoing calcium transients localized to their stalks within the IPL and mediated by glial $\mathrm{M}_{1} \mathrm{mAChRs}$ (Rosa et al., 2015; Tworig et al., 2021). As waves shift from cholinergic to glutamatergic circuits, Müller glial lateral processes and stalks continue to undergo wave-evoked calcium transients via activation of ionotropic glutamate receptors (iGluRs) and $\mathrm{M}_{1}$ mAChRs (Figure 6B). This is associated with electrogenic glutamate uptake during each glutamatergic wave which slightly depolarizes Müller glia (Akrouh and Kerschensteiner, 2013).

Glial participation in developing visual circuits is a feature conserved across several species. In zebrafish retina, wave-evoked Müller glial calcium transients are thought to occur via a combination of glia-specific glutamate transporters and calciumpermeable AMPA receptors (Zhang et al., 2019). In Xenopus optic tectum, where correlated neural activity during development is driven by vision rather than spontaneous activity (Demas et al., 2012), radial astrocytes undergo calcium transients mediated by reversal of sodium-calcium exchangers (NCX) following lightevoked glutamate release from neurons and uptake by glia (Benfey et al., 2021). Glial participation in patterned activity within developing visual areas is not exclusive to vertebrates; in the developing Drosophila optic lobe, columnar astrocytes undergo phasic changes in intracellular calcium levels which are negatively correlated with nearby bursts of spontaneous neuronal activity (Akin et al., 2019).

\section{Activity-Dependent Glial Responses}

The downstream effects of activity-evoked calcium signaling in Müller glia and other visual system astroglia have not been defined. One might infer based on studies in other systems that these responses could regulate glial morphology (Tremblay et al., 2009; Molotkov et al., 2013; Bernardinelli et al., 2014), gene expression (Farhy-Tselnicker et al., 2021), or release of synaptic or vascular modulators to guide circuit development and maintain homeostasis. A recent study from our lab explored the potential for activity-evoked Müller glial calcium transients to affect lateral process morphology and found that both intracellular calcium transients and neuronal activity are dispensable for motility of processes in the IPL, and that lateral process distribution is normal when retinal waves are perturbed (Tworig et al., 2021). These findings suggest that other undetermined functions of activity-evoked calcium signaling in Müller glia are at play during retinal waves. This contrasts with studies of perisynaptic brain astrocytes and Xenopus radial glia, which exhibit branch motility 


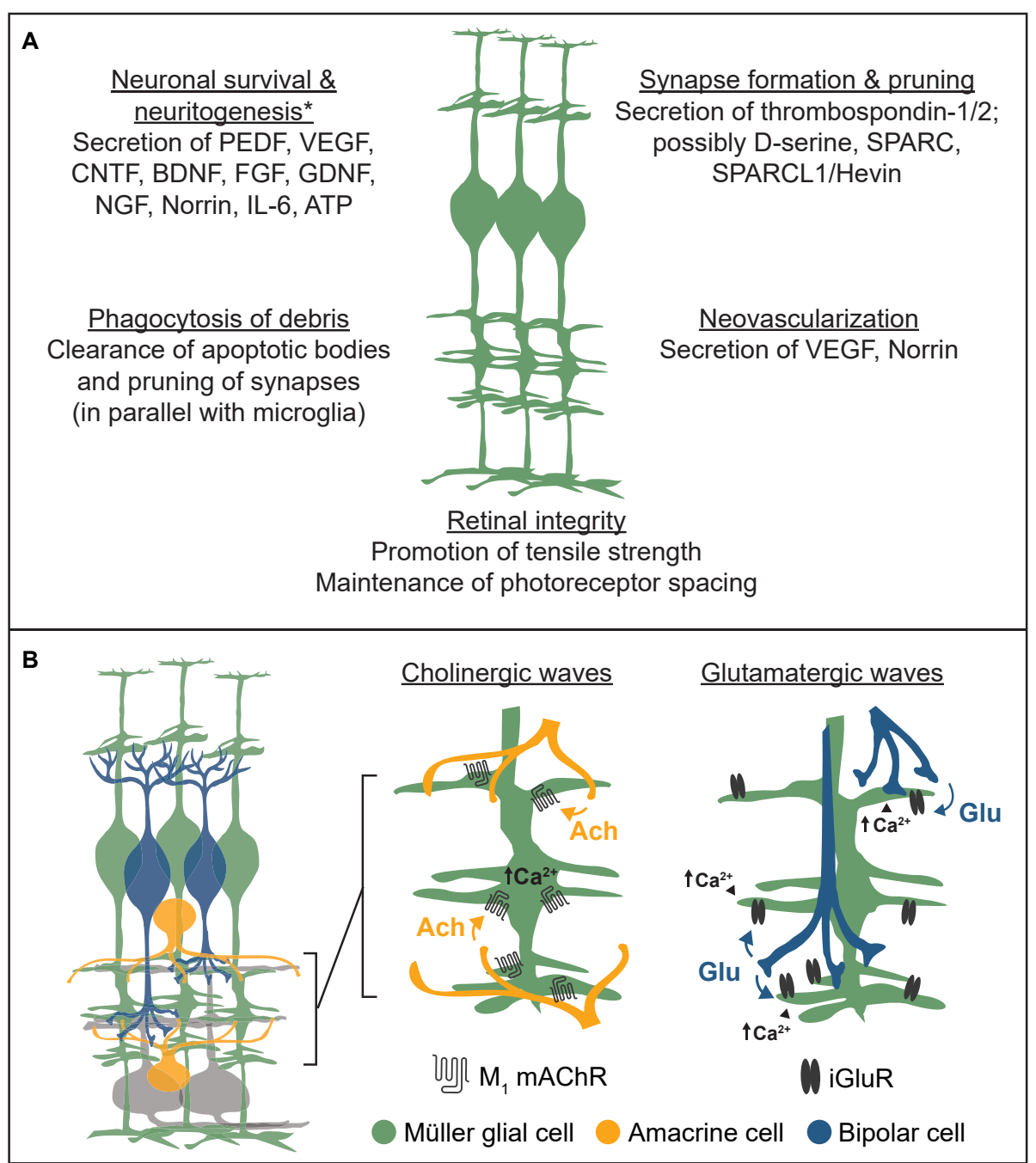

FIGURE 6 | Summary of the roles of Müller glia in retinal development. (A) Müller glia engage in broad aspects of retinal development through the release of neurotrophins, synaptogenic proteins, and other trophic factors, while also clearing cellular debris and maintaining retinal integrity. Examples listed are non-exhaustive. *Müller glia-derived trophic factors promoting neuronal survival or neuritogenesis were primarily identified in neuron-glia coculture experiments. (B) Summary of Müller glial responses to cholinergic and glutamatergic retinal waves. Left, schematic diagram of basic inner retinal circuits showing bipolar cells (blue), Müller glia (green), amacrine cells (orange), and ganglion cells (gray) intermingling within the inner plexiform layer (IPL). Middle, during cholinergic retinal waves, starburst amacrine cells spontaneously release acetylcholine (ACh), which activates Müller glial $\mathrm{M}_{1}$ muscarinic acetylcholine receptors (mAChRs) following spillover from synapses. This induces calcium transients in Müller glia primarily localized to their stalks within the inner plexiform layer. Right, during glutamatergic retinal waves, bipolar cells spontaneously release glutamate (Glu), which activates Müller glial ionotropic glutamate receptors (iGluRs) following synaptic spillover, inducing calcium transients primarily localized to glial lateral processes within the IPL.

in response to neuronal activity (Tremblay et al., 2009; Molotkov et al., 2013; Bernardinelli et al., 2014).

Studies across brain regions have shown that neuronal activity can upregulate glial neurotransmitter transport, thereby tuning the fidelity of synaptic transmission via spatial buffering and preventing excitotoxic injury. This has been shown using cultured Müller glia, in which glutamate stimulation leads to upregulated expression of the glutamate transporter GLAST concomitantly with downregulation of glial NMDA receptors (Taylor et al., 2003; López-Colomé et al., 2016). It has been reported that NMDAR activation in Müller glia co-cultured with RGCs promotes RGC survival via upregulation of glial glutamate transport, thereby preventing excitotoxicity (Furuya et al., 2012). In rodent retina, GLAST is upregulated by Müller glia within the first two postnatal weeks (Pow and Barnett, 1999), suggesting a possible link between retinal wave-evoked Müller glial calcium transients and transporter expression.

Reflective of the bidirectional nature of neuron-glia signaling, Müller glial glutamate transport has been shown to tune the duration and frequency of retinal waves in zebrafish, and their blockade abolishes retinal waves completely, likely due to elevated extracellular glutamate concentration (Zhang et al., 2019). Similarly in developing Xenopus, blocking NCX-driven glial calcium transients during light-evoked activity leads to 
enhancement of neuronal responses, possibly resulting from impaired insertion of glutamate transporters into the glial membrane (Ibáñez et al., 2019; Benfey et al., 2021). In mouse retina, glutamate uptake in part by Müller glia seems to promote sequential activation of $\mathrm{ON}$ and then OFF RGCs during retinal waves (Akrouh and Kerschensteiner, 2013). Blockade of glutamate transport removes this sequential activation, inducing ON and OFF RGCs to fire synchronously during waves. This change in the spatiotemporal pattern of RGC activation has implications for development of independent downstream ON and OFF pathways, as observed in the ferret visual system (Lee et al., 2002).

In addition to upregulated glutamate transport, Müller glia undergo developmental changes in other membrane proteins capable of modulating neurotransmission or maintaining homeostasis. In rabbit retina, postnatal upregulation of the inward rectifier potassium channel Kir4.1 and aquaporin4 accompany developmental changes in glial membrane properties including gradual hyperpolarization, reduced membrane resistance, increased capacitance, enhanced potassium conductance, and resistance to swelling under osmotic stress (Pannicke et al., 2002; Bosco et al., 2005; Wurm et al., 2006). Expression and subcellular localization of Kir4.1 and aquaporin4 in Müller glia are governed in part by the extracellular cell adhesion molecule laminin (Hirrlinger et al., 2011). It is enticing to consider whether retinal waves play a role in this developmental increase of Kir4.1 and aquaporin-4 expression.

Along with possible modulation of membrane protein expression in Müller glia, retinal wave-evoked glial calcium transients may induce release of synaptic modulators. One fascinating example is the vision-dependent release from Müller glia of Acyl-CoA-binding protein (ACBP), which desensitizes $\mathrm{GABA}_{A}$ receptors (Barmack et al., 2004). Long-term horizontal optokinetic stimulation in rabbits enhances ACBP expression and phosphorylation, which increases its affinity for $\mathrm{GABA}_{A}$

\section{REFERENCES}

Ackerman, S. D., Perez-Catalan, N. A., Freeman, M. R., and Doe, C. Q. (2021). Astrocytes close a motor circuit critical period. Nature 592, 414-420.

Akin, O., Bajar, B. T., Keles, M. F., Frye, M. A., and Zipursky, S. L. (2019). Cell-typeSpecific Patterned Stimulus-Independent Neuronal Activity in the Drosophila Visual System during Synapse Formation. Neuron 101, 894.e-904.e.

Akrouh, A., and Kerschensteiner, D. (2013). Intersecting Circuits Generate Precisely Patterned Retinal Waves. Neuron 79:322. doi: 10.1016/j.neuron.2013. 05.012

Albrecht, D., López-Murcia, F. J., Pérez-González, A. P., Lichtner, G., Solsona, C., and Llobet, A. S. P. A. R. C. (2012). prevents maturation of cholinergic presynaptic terminals. Mol. Cell. Neurosci. 49, 364-374. doi: 10.1016/j.mcn. 2012.01.005

Allen, N. J., and Lyons, D. A. (2018). Glia as architects of central nervous system formation and function. Science 362, 181-185. doi: 10.1126/science.aat 0473

Arroyo, D. A., and Feller, M. B. (2016). Spatiotemporal Features of Retinal Waves Instruct the Wiring of the Visual Circuitry. Front. Neural Circuits 10:54. doi: 10.3389/fncir.2016.00054

Baba, Y., Aihara, Y., and Watanabe, S. (2015). MicroRNA-7a regulates Müller glia differentiation by attenuating Notch3 expression. Exp. Eye Res. 138, 59-65. doi: 10.1016/j.exer.2015.06.022 receptors. This occurs only when stimulated in the preferred posterior-to-anterior direction and is associated with reduced gain of the optokinetic reflex. This is thought to result from reduced inhibitory effect of GABA on horizontal motionpreferring ON-OFF DSGCs following ACBP secretion (Barmack et al., 2004). ACBP production and phosphorylation in Müller glia has been shown to occur directly following stimulation with $\mathrm{KCl}$ and activation of protein kinase C (PKC) (Qian et al., 2008). As such, $M_{1}$ mAChR-mediated PKC activation during cholinergic retinal waves could promote secretion of ACBP and influence the spatiotemporal properties of waves or the maturation of direction selective circuits by dampening the effect of GABA on postsynaptic neurons.

Neuronal activity may play a role in the release from Müller glia of any of the trophic molecules and synaptic modulators mentioned in previous sections, including thrombospondins and D-serine. As previously described, glutamate enhances secretion of neurotrophic factors such as BDNF and NGF from cultured Müller glia (Taylor et al., 2003), but whether this occurs in vivo is unknown. Future work employing targeted pharmacological and genetic perturbations along with selective sensors for synaptic modulators will aid in determining whether this is the case.

\section{AUTHOR CONTRIBUTIONS}

JT wrote the manuscript. MF made minor edits. Both authors contributed to the article and approved the submitted version.

\section{FUNDING}

JT was supported by the National Science Foundation Graduate Research Fellowship (DGE 1752814). JT and MF were supported by NIH grants R01EY019498, R01EY013528, and P30EY003176.

Bachleda, A. R., Pevny, L. H., and Weiss, E. R. (2016). Sox2-Deficient Müller Glia Disrupt the Structural and Functional Maturation of the Mammalian Retina. Invest. Ophthalmol. Vis. Sci. 57, 1488-1499. doi: 10.1167/iovs.15-17994

Bai, Y., Ma, J., Guo, J., Wang, J., Zhu, M., Chen, Y., et al. (2009). Müller cell-derived VEGF is a significant contributor to retinal neovascularization. J. Pathol. 219, 446-454. doi: 10.1002/path.2611

Baldwin, K. T., Tan, C. X., Strader, S. T., Jiang, C., Savage, J. T., Elorza-Vidal, X., et al. (2021). HepaCAM controls astrocyte self-organization and coupling. Neuron 109, 2427.e-2442.e. doi: 10.1016/j.neuron.2021.05.025

Bansal, A., Singer, J. H., Hwang, B. J., Xu, W., Beaudet, A., and Feller, M. B. (2000). Mice Lacking Specific Nicotinic Acetylcholine Receptor Subunits Exhibit Dramatically Altered Spontaneous Activity Patterns and Reveal a Limited Role for Retinal Waves in Forming ON and OFF Circuits in the Inner Retina. J. Neurosci. 20, 7672-7681. doi: 10.1523/JNEUROSCI.20-20-07672.2000

Barmack, N. H., Bilderback, T. R., Liu, H., Qian, Z., and Yakhnitsa, V. (2004). Activity-Dependent Expression of Acyl-Coenzyme A-Binding Protein in Retinal Muller Glial Cells Evoked by Optokinetic Stimulation. J Neurosci. 24, 1023-1033. doi: 10.1523/JNEUROSCI.3936-03.2004

Bassett, E. A., and Wallace, V. A. (2012). Cell fate determination in the vertebrate retina. Trends Neurosci. 35, 565-573.

Belmonte, K. E., McKinnon, L. A., and Nathanson, N. M. (2000). Developmental expression of muscarinic acetylcholine receptors in chick retina: selective induction of M2 muscarinic receptor expression in ovo by a factor secreted by 
muller glial cells. J. Neurosci. 20, 8417-8425. doi: 10.1523/JNEUROSCI.20-2208417.2000

Benfey, N. J., Li, V. J., Schohl, A., and Ruthazer, E. S. (2021). Sodium-calcium exchanger mediates sensory-evoked glial calcium transients in the developing retinotectal system. Cell Rep. 37:109791. doi: 10.1016/j.celrep.2021.109791

Bernardinelli, Y., Randall, J., Janett, E., Nikonenko, I., König, S., Jones, E. V., et al. (2014). Activity-dependent structural plasticity of perisynaptic astrocytic domains promotes excitatory synapse stability. Curr. Biol. 24, 1679-1688. doi: 10.1016/j.cub.2014.06.025

Blackshaw, S., and Sanes, J. R. (2021). Turning lead into gold: Reprogramming retinal cells to cure blindness. J. Clin. Invest. 131:e146134. doi: 10.1172/ JCI146134

Blankenship, A., and Feller, M. (2010). Mechanisms underlying spontaneous patterned activity in developing neural circuits. Nat. Rev. Neurosci. 11, 18-29. doi: $10.1038 / \mathrm{nrn} 2759$

Blankenship, A. G., Ford, K. J., Johnson, J., Seal, R. P., Edwards, R. H., Copenhagen, D. R., et al. (2009). Synaptic and extrasynaptic factors governing glutamatergic retinal waves. Neuron 62, 230-241. doi: 10.1016/j.neuron.2009.03.015

Bosco, A., Cusato, K., Niccbia, G. P., Frigeri, A., and Spray, D. C. (2005). A Developmental Switch in the Expression of Aquaporin-4 and Kir4.1 from Horizontal to Müller Cells in Mouse Retina. Invest. Ophthalmol. Vis. Sci. 46, 3869-3875. doi: 10.1167/iovs.05-0385

Cepko, C. (2014). Intrinsically different retinal progenitor cells produce specific types of progeny. Nat. Rev. Neurosci. 15, 615-627. doi: 10.1038/nrn3767

Cepko, C. L., Austin, C. P., Yang, X., Alexiades, M., and Ezzeddine, D. (1996). Cell fate deternination in the vertebrate retina. Trends Neurosci. 93, 589-595.

Charlton-Perkins, M., Almeida, A. D., MacDonald, R. B., and Harris, W. A. (2019). Genetic control of cellular morphogenesis in Müller glia. Glia 67, 1401-1411. doi: 10.1002/glia.23615

Charlton-Perkins, M., Whitaker, S. L., Fei, Y., Xie, B., Li-Kroeger, D., Gebelein, B., et al. (2011). Prospero and Pax2 combinatorially control neural cell fate decisions by modulating Ras- and Notch-dependent signaling. Neural Dev. 6:20. doi: 10.1186/1749-8104-6-20

Chavira-Suárez, E., Ramírez, M., and Lamas, M. (2008). d-Serine/N-methyld-aspartate receptor signaling decreases DNA-binding activity of the transcriptional repressor DREAM in Müller glia from the retina. Neurosci. Lett. 432, 121-126. doi: 10.1016/j.neulet.2007.12.021

Choi, B., Chen, Y., and Desplan, C. (2021). Building a circuit through correlated spontaneous neuronal activity in the developing vertebrate and invertebrate visual systems. Genes Dev. 35, 677-691. doi: 10.1101/gad.348241.121

Clark, B. S., Stein-O’Brien, G. L., Shiau, F., Cannon, G. H., Davis-Marcisak, E., Sherman, T., et al. (2019). Single cell RNA-Seq analysis of retinal development identifies NFI factors as regulating mitotic exit and late-born cell specification. Neuron 102:1111. doi: 10.1016/j.neuron.2019.04.010

Close, J. L., Gumuscu, B., and Reh, T. A. (2005). Retinal neurons regulate proliferation of postnatal progenitors and Müller glia in the rat retina via TGF $\beta$ signaling. Development 132, 3015-3026. doi: 10.1002/cne.22741

Close, J. L., Liu, J., Gumuscu, B., and Reh, T. A. (2006). Epidermal growth factor receptor expression regulates proliferation in the postnatal rat retina. Glia 54, 94-104. doi: 10.1002/glia.20361

Davis, N., Mor, E., and Ashery-Padan, R. (2011). Roles for Dicer1 in the patterning and differentiation of the optic cup neuroepithelium. Development 138, 127138. doi: $10.1242 /$ dev. 053637

Demas, J. A., Payne, H., and Cline, H. T. (2012). Vision Drives Correlated Activity without Patterned Spontaneous Activity in Developing Xenopus Retina. Dev. Neurobiol. 72:537. doi: 10.1002/dneu.20880

Diaz, C. M., Macnab, L. T., Williams, S. M., Sullivan, R. K. P., and Pow, D. V. (2007). EAAT1 and d-serine expression are early features of human retinal development. Exp. Eye Res. 84, 876-885. doi: 10.1016/j.exer.2007.01.008

Diniz, L. P., Almeida, J. C., Tortelli, V., Lopes, C. V., Setti-Perdigão, P., Stipursky, J., et al. (2012). Astrocyte-induced Synaptogenesis Is Mediated by Transforming Growth Factor $\beta$ Signaling through Modulation of d-Serine Levels in Cerebral Cortex Neurons *. J. Biol. Chem. 287, 41432-41445. doi: 10.1074/jbc.M112. 380824

Dixon, M. A., Greferath, U., Fletcher, E. L., and Jobling, A. I. (2021). The Contribution of Microglia to the Development and Maturation of the Visual System. Front. Cell. Neurosci. 15:659843. doi: 10.3389/fncel.2021.65 9843
Dun, Y., Duplantier, J., Roon, P., Martin, P. M., Ganapathy, V., and Smith, S. B. (2008). Serine racemase expression and d-serine content are developmentally regulated in neuronal ganglion cells of the retina. J. Neurochem. 104, 970-978. doi: 10.1111/j.1471-4159.2007.05015.x

Egensperger, R., Maslim, J., Bisti, S., Holländer, H., and Stone, J. (1996). Fate of DNA from retinal cells dying during development: uptake by microglia and macroglia (Müller cells). Dev. Brain Res. 97, 1-8. doi: 10.1016/s0165-3806(96) 00119-8

Elliott, J., Jolicoeur, C., Ramamurthy, V., and Cayouette, M. (2008). Ikaros Confers Early Temporal Competence to Mouse Retinal Progenitor Cells. Neuron 60, 26-39. doi: 10.1016/j.neuron.2008.08.008

Eroglu, Ç, Allen, N. J., Susman, M. W., O’Rourke, N. A., Park, C. Y., Özkan, E., et al. (2009). Gabapentin Receptor $\alpha 2 \delta-1$ Is a Neuronal Thrombospondin Receptor Responsible for Excitatory CNS Synaptogenesis. Cell 139, 380-392. doi: 10.1016/j.cell.2009.09.025

Farhy-Tselnicker, I., Boisvert, M. M., Liu, H., Dowling, C., Erikson, G. A., BlancoSuarez, E., et al. (2021). Activity-dependent modulation of synapse-regulating genes in astrocytes. Elife 10:70514. doi: 10.7554/eLife.70514

Ford, K. J., Félix, A. L., and Feller, M. B. (2012). Cellular Mechanisms Underlying Spatiotemporal Features of Cholinergic Retinal Waves. J. Neurosci. 32, 850-863. doi: 10.1523/JNEUROSCI.5309-12.2012

Francisco-Morcillo, J., Hidalgo-Sánchez, M., and Martín-Partido, G. (2004). Spatial and temporal patterns of apoptosis during differentiation of the retina in the turtle. Anat. Embryol. 208, 289-299. doi: 10.1007/s00429-004-0398-x

Franze, K., Grosche, J., Skatchkov, S., Schinkinger, S., Foja, C., Schild, D., et al. (2007). Müller cells are living optical fibers in the vertebrate retina. Proc. Natl. Acad. Sci. U. S. A. 104, 8287-8292. doi: 10.1073/pnas.0611180104

Furukawa, T., Mukherjee, S., Bao, Z. Z., Morrow, E. M., and Cepko, C. L. (2000). rax, Hes1, and notch1 Promote the Formation of Müller Glia by Postnatal Retinal Progenitor Cells. Neuron 26, 383-394. doi: 10.1016/s0896-6273(00) 81171-x

Furuya, T., Pan, Z., and Kashiwagi, K. (2012). Role of retinal glial cell glutamate transporters in retinal ganglion cell survival following stimulation of NMDA receptor. Curr. Eye Res. 37, 170-178. doi: 10.3109/02713683.2011.645105

García, M., Forster, V., Hicks, D., and Vecino, E. (2002). Effects of Müller glia on cell survival and neuritogenesis in adult porcine retina in vitro. Investig. Ophthalmol. Vis. Sci. 43, 3735-3743.

Georgi, S. A., and Reh, T. A. (2010). Dicer Is Required for the Transition from Early to Late Progenitor State in the Developing Mouse Retina. J. Neurosci. 30:4048. doi: 10.1523/JNEUROSCI.4982-09.2010

Goldman, D. (2014). Müller glia cell reprogramming and retina regeneration. Nat. Rev. Neurosci. 15:431.

Goureau, O., Rhee, K., and Yang, X.-J. (2004). Ciliary Neurotrophic Factor Promotes Müller Glia Differentiation from the Postnatal Retinal Progenitor Pool. . Dev. Neurosci. 26:359. doi: 10.1159/000082278

Guidry, C., Bradley, K. M., and King, J. L. (2003). Tractional force generation by human müller cells: growth factor responsiveness and integrin receptor involvement. Invest. Ophthalmol. Vis. Sci. 44, 1355-1363. doi: 10.1167/iovs.020046

Hansen, K. H., Bracken, A. P., Pasini, D., Dietrich, N., Gehani, S. S., Monrad, A., et al. (2008). A model for transmission of the H3K27me3 epigenetic mark. Nat. Cell Biol. 10, 1291-1300. doi: 10.1038/ncb1787

Harada, T., Harada, C., Kohsaka, S., Wada, E., Yoshida, K., Ohno, S., et al. (2002). Microglia-Müller Glia Cell Interactions Control Neurotrophic Factor Production during Light-Induced Retinal Degeneration. J. Neurosci. 22, 92289236.

Hasel, P., Dando, O., Jiwaji, Z., Baxter, P., Todd, A. C., Heron, S., et al. (2017). Neurons and neuronal activity control gene expression in astrocytes to regulate their development and metabolism. Nat. Commun. 8:15132.

Hauck, S. M., Suppmann, S., and Ueffing, M. (2003). Proteomic profiling of primary retinal Müller glia cells reveals a shift in expression patterns upon adaptation to in vitro conditions. Glia 44, 251-263. doi: 10.1002/glia.10292

Henrique, D., Hirsinger, E., Adam, J., Roux, I., Le Pourquié, O., Ish-Horowicz, D., et al. (1997). Maintenance of neuroepithelial progenitor cells by DeltaNotch signalling in the embryonic chick retina. Curr. Biol. 7, 661-670. doi: 10.1016/s0960-9822(06)00293-4

Hirrlinger, P. G., Pannicke, T., Winkler, U., Claudepierre, T., Varshney, S., Schulze, C., et al. (2011). Genetic Deletion of Laminin Isoforms $\beta 2$ and $\gamma 3$ Induces a 
Reduction in Kir4.1 and Aquaporin-4 Expression and Function in the Retina. PLoS One 6:e16106. doi: 10.1371/journal.pone.0016106

Hojo, M., Ohtsuka, T., Hashimoto, N., Gradwohl, G., Guillemot, F., and Kageyama, R. (2000). Glial cell fate specification modulated by the bHLH gene Hes5 in mouse retina. Development 127, 2515-2522.

Hoon, M., Okawa, H., Santina, L., and Wong, R. O. (2014). Functional Architecture of the Retina: Development and Disease. . Prog. Retin. Eye Res. 42:44. doi: 10.1016/j.preteyeres.2014.06.003

Hu, Q., Zhang, L., Wen, J., Wang, S., Li, M., Feng, R., et al. (2010). The Egf Receptor-Sox2-Egf Receptor Feedback Loop Positively Regulates the SelfRenewal of Neural Precursor Cells. Stem Cells 28, 279-286. doi: 10.1002/ stem. 246

Hughes, W. F., and Lavelle, A. (1975). The effects of early tectal lesions on development in the retinal ganglion cell layer of chick embryos. J. Comp. Neurol. 163, 265-283. doi: 10.1002/cne.901630303

Ibáñez, I., Bartolomé-Martín, D., Piniella, D., Giménez, C., and Zafra, F. (2019). Activity dependent internalization of the glutamate transporter GLT-1 requires calcium entry through the NCX sodium/calcium exchanger. Neurochem. Int. 123, 125-132. doi: 10.1016/j.neuint.2018.03.012

Iida, A., Iwagawa, T., Baba, Y., Satoh, S., Mochizuki, Y., Nakauchi, H., et al. (2015). Roles of histone H3K27 trimethylase Ezh2 in retinal proliferation and differentiation. Dev. Neurobiol. 75, 947-960. doi: 10.1002/dneu.22261

Jadhav, A. P., Cho, S.-H., and Cepko, C. L. (2006). Notch activity permits retinal cells to progress through multiple progenitor states and acquire a stem cell property. Proc. Natl. Acad. Sci. US A. 103:18998. doi: 10.1073/pnas.0608155103

Keeley, P., Eglen, S., and Reese, B. (2020). From random to regular: variation in the patterning of retinal mosaics. J. Comp. Neurol. 528, 2135-2160. doi: $10.1002 /$ cne. 24880

Kerschensteiner, D. (2016). Glutamatergic retinal waves. Front. Neural Circuits 10:38. doi: 10.3389/fncir.2016.00038

Koh, S., Chen, W. J., Dejneka, N. S., Harris, I. R., Lu, B., Girman, S., et al. (2018). Subretinal Human Umbilical Tissue-Derived Cell Transplantation Preserves Retinal Synaptic Connectivity and Attenuates Müller Glial Reactivity. J. Neurosci. 38, 2923-2943. doi: 10.1523/JNEUROSCI.1532-17.2018

Koh, S., Roy, S., Eroglu, O., Strader, S., Chen, W. J., Kay, J. N., et al. (2019). Thrombospondin-1 Promotes Circuit-Specific Synapse Formation via $\beta 1$ Integrin. bioRxiv 2019:866590. doi: 10.1101/866590

Kohn, A., Rutkowski, T. P., Liu, Z., Mirando, A. J., Zuscik, M. J., O’Keefe, R. J., et al. (2015). Notch signaling controls chondrocyte hypertrophy via indirect regulation of Sox9. Bone Res. 3, 1-12. doi: 10.1038/boneres.2015.21

Kucukdereli, H., Allen, N. J., Lee, A. T., Feng, A., Ozlu, M. I., Conatser, L. M., et al. (2011). Control of excitatory CNS synaptogenesis by astrocyte-secreted proteins hevin and SPARC. Proc. Natl. Acad. Sci. U S A. 108, E440-E449. doi: $10.1073 /$ pnas. 1104977108

La Torre, A., Georgi, S., and Reh, T. A. (2013). Conserved microRNA pathway regulates developmental timing of retinal neurogenesis. Proc. Natl. Acad. Sci. U S A. 110, E2362. doi: 10.1073/pnas.1301837110

La Vail, M. M., Rapaport, D. H., and Rakic, P. (1991). Cytogenesis in the monkey retina. J. Comp. Neurol. 309, 86-114. doi: 10.1002/cne.903090107

Lamas, M., Lee-Rivera, I., Ramírez, M., and López-Colomé, A. M. (2007). d-Serine regulates $\mathrm{CREB}$ phosphorylation induced by NMDA receptor activation in Müller glia from the retina. Neurosci. Lett. 427, 55-60. doi: 10.1016/j.neulet. 2007.09.009

Lange, J., Yafai, Y., Noack, A., Yang, X. M., Munk, A.-B., Krohn, S., et al. (2012). The axon guidance molecule Netrin-4 is expressed by Müller cells and contributes to angiogenesis in the retina. Glia 60, 1567-1578. doi: 10.1002/glia.22376

Lasorella, A., Uo, T., and Iavarone, A. (2002). Id proteins at the cross-road of development and cancer. Oncogene 20, 8326-8333. doi: 10.1038/sj.onc.1205093

Lavialle, M., Aumann, G., Anlauf, E., Pröls, F., Arpin, M., and Derouiche, A. (2011). Structural plasticity of perisynaptic astrocyte processes involves ezrin and metabotropic glutamate receptors. Proc. Natl. Acad. Sci. 108, 12915-12919. doi: $10.1073 /$ pnas.1100957108

Lee, C. W., Eglen, S. J., and Wong, R. O. L. (2002). Segregation of ON and OFF retinogeniculate connectivity directed by patterned spontaneous activity. J. Neurophysiol. 88, 2311-2321. doi: 10.1152/jn.00372.2002

Levine, E. M., Close, J., Fero, M., Ostrovsky, A., and Reh, T. A. (2000). p27Kip1 Regulates Cell Cycle Withdrawal of Late Multipotent Progenitor Cells in the Mammalian Retina. Dev. Biol. 219, 299-314. doi: 10.1006/dbio.2000.9622
Li, F., Jiang, D., and Samuel, M. A. (2019). Microglia in the developing retina. Neural Dev. 14, 1-13.

Lillien, L. (1995). Changes in retinal cell fate induced by overexpression of EGF receptor. Nature 377, 158-161. doi: 10.1038/377158a0

Lillien, L., and Wancio, D. (1998). Changes in Epidermal Growth Factor Receptor Expression and Competence to Generate Glia Regulate Timing and Choice of Differentiation in the Retina. Mol. Cell. Neurosci. 10, 296-308. doi: 10.1006/ mcne.1997.0659

Livesey, F. J., and Cepko, C. L. (2001). Vertebrate neural cell-fate determination: Lessons from the retina. Nat. Rev. Neurosci. 2, 109-118. doi: 10.1038/35053522

López-Colomé, A. M., López, E., Mendez-Flores, O. G., and Ortega, A. (2016). Glutamate Receptor Stimulation Up-Regulates Glutamate Uptake in Human Müller Glia Cells. Neurochem. Res. 41, 1797-1805. doi: 10.1007/s11064-0161895-z

Louvi, A., and Artavanis-Tsakonas, S. (2006). Notch signalling in vertebrate neural development. Nat. Rev. Neurosci. 7, 93-102. doi: 10.1038/nrn1847

MacDonald, R. B., Randlett, O., Oswald, J., Yoshimatsu, T., Franze, K., and Harris, W. A. (2015). Müller glia provide essential tensile strength to the developing retina. J. Cell Biol. 210, 1075-1083. doi: 10.1083/jcb.201503115

Marín-Teva, J. L., Cuadros, M. A., Calvente, R., Almendros, A., and Navascués, J. (1999). Naturally Occurring Cell Death and Migration of Microglial Precursors in the Quail Retina During Normal Development. J. Comp. Neurol. 412, 255-275. doi: 10.1002/(sici)1096-9861(19990920)412:2<255::aid-cne6> 3.0.co; $2-\mathrm{h}$

Melo, J., de Clark, B. S., and Blackshaw, S. (2016a). Multiple intrinsic factors act in concert with Lhx2 to direct retinal gliogenesis. Sci. Rep. 6:32757. doi: $10.1038 /$ srep 32757

Melo, J., de Zibetti, C., Clark, B. S., Hwang, W., Miranda-Angulo, A. L., Qian, J., et al. (2016b). Lhx2 Is an Essential Factor for Retinal Gliogenesis and Notch Signaling. J. Neurosci. 36:2391. doi: 10.1523/JNEUROSCI.3145-15.2016

Metea, M. R., and Newman, E. A. (2006). Glial Cells Dilate and Constrict Blood Vessels: A Mechanism of Neurovascular Coupling. J. Neurosci. 26, 2862-2870. doi: 10.1523/JNEUROSCI.4048-05.2006

Miller, S. J., Philips, T., Kim, N., Dastgheyb, R., Chen, Z., Hsieh, Y. C., et al. (2019). Molecularly defined cortical astroglia subpopulation modulates neurons via secretion of Norrin. Nat. Neurosci. 22, 741-752. doi: 10.1038/s41593-0190366-7

Mizeracka, K., DeMaso, C. R., and Cepko, C. L. (2013). Notch1 is required in newly postmitotic cells to inhibit the rod photoreceptor fate. Development 140 , 3188-3197. doi: 10.1242/dev.090696

Molotkov, D., Zobova, S., Arcas, J. M., and Khiroug, L. (2013). Calcium-induced outgrowth of astrocytic peripheral processes requires actin binding by Profilin1. Cell Calcium 53, 338-348. doi: 10.1016/j.ceca.2013.03.001

Müller, H. (1851). Zur Histologie der Netzhaut. Zeitschrift für Wiss Zool 3, 234237.

Musada, G. R., Dvoriantchikova, G., Myer, C., Ivanov, D., Bhattacharya, S. K., and Hackam, A. S. (2020). The effect of extrinsic Wnt/ $\beta$-catenin signaling in Muller glia on retinal ganglion cell neurite growth. Dev. Neurobiol. 80, 98-110. doi: 10.1002/dneu.22741

Nagai, J., Rajbhandari, A. K., Gangwani, M. R., Hachisuka, A., Coppola, G., Masmanidis, S. C., et al. (2019). Hyperactivity with disrupted attention by activation of an astrocyte synaptogenic cue. Cell 177:1280. doi: 10.1016/j.cell. 2019.03.019

Nagashima, M., Hadidjojo, J., Barthel, L. K., Lubensky, D. K., and Raymond, P. A. (2017). Anisotropic Müller glial scaffolding supports a multiplex lattice mosaic of photoreceptors in zebrafish retina. Neural Dev. 12, 1-20. doi: 10.1186/ s13064-017-0096-z

Nelson, B. R., Ueki, Y., Reardon, S., Karl, M. O., Georgi, S., Hartman, B. H., et al. (2011). Genome-Wide Analysis of Müller Glial Differentiation Reveals a Requirement for Notch Signaling in Postmitotic Cells to Maintain the Glial Fate. PLoS One 6:e22817. doi: 10.1371/journal.pone.002 2817

Nomura-Komoike, K., Saitoh, F., and Fujieda, H. (2020). Phosphatidylserine recognition and Racl activation are required for Müller glia proliferation, gliosis and phagocytosis after retinal injury. Sci. Rep. 10, 1-11. doi: 10.1038/ s41598-020-58424-6

Paisley, C. E., and Kay, J. N. (2021). Seeing stars: Development and function of retinal astrocytes. Dev. Biol. 478, 144-154. doi: 10.1016/j.ydbio.2021.07.007 
Pannicke, T., Bringmann, A., and Reichenbach, A. (2002). Electrophysiological characterization of retinal Müller glial cells from mouse during postnatal development: Comparison with rabbit cells. Glia 38, 268-272. doi: 10.1002/glia. 10068

Patel, A. K., Surapaneni, K., Yi, H., Nakamura, R. E. I., Karli, S. Z., Syeda, S., et al. (2015). Activation of $\mathrm{Wnt} / \beta$-catenin signaling in Muller glia protects photoreceptors in a mouse model of inherited retinal degeneration. Neuropharmacology 0:1. doi: 10.1016/j.neuropharm.2014.11.015

Pena, J., Dulger, N., Singh, T., Zhou, J., Majeska, R., Redenti, S., et al. (2018). Controlled microenvironments to evaluate chemotactic properties of cultured Müller glia. Exp. Eye Res. 173, 129-137. doi: 10.1016/j.exer.2018.05.005

Peng, Y. R., Shekhar, K., Yan, W., Herrmann, D., Sappington, A., Bryman, G. S., et al. (2019). Molecular Classification and Comparative Taxonomics of Foveal and Peripheral Cells in Primate Retina. Cell 176, 1222.e-1237.e. doi: 10.1016/j. cell.2019.01.004

Phillips, J. B., Blanco-Sanchez, B., Lentz, J. J., Tallafuss, A., Khanobdee, K., Sampath, S., et al. (2011). Harmonin (Ush1c) is required in zebrafish Müller glial cells for photoreceptor synaptic development and function. Dis. Model. Mech. 4:786. doi: 10.1242/dmm.006429

Poché, R. A., Furuta, Y., Chaboissier, M.-C., Schedl, A., and Behringer, R. R. (2008). Sox9 Is Expressed in Mouse Multipotent Retinal Progenitor Cells and Functions in Müller Glial Cell Development. J. Comp. Neurol. 510:237. doi: $10.1002 / \mathrm{cne} .21746$

Pow, D. V., and Barnett, N. L. (1999). Changing patterns of spatial buffering of glutamate in developing rat retinae are mediated by the Müller cell glutamate transporter GLAST. Cell Tissue Res. 297, 57-66. doi: 10.1007/s00441005 1333

Prada, C., Puga, J., Perez,-Mendez Lopez, R., and Ramirez, G. (1991). Spatial and Temporal Patterns of Neurogenesis in the Chick Retina. Eur. J. Neurosci. 3, 559-569. doi: 10.1111/j.1460-9568.1991.tb00843.x

Qian, Z., Bilderback, T. R., and Barmack, N. H. (2008). Acyl coenzyme A-binding protein $(\mathrm{ACBP})$ is phosphorylated and secreted by retinal Müller astrocytes following protein kinase C activation. J. Neurochem. 105, 1287-1299. doi: 10. $1111 /$ j.1471-4159.2008.05229.x

Quintero, H., and Lamas, M. (2018). microRNA expression in the neural retina: Focus on Müller glia. J. Neurosci. Res. 96, 362-370.

Ramon y Cajal, S. (1893). La rétine des vertébrés. Cellule 9, 120-258.

Randlett, O., MacDonald, R. B., Yoshimatsu, T., Almeida, A. D., Suzuki, S. C., Wong, R. O., et al. (2013). Cellular Requirements for Building a Retinal Neuropil. Cell Rep. 3:282. doi: 10.1016/j.celrep.2013.01.020

Reese, B. E., and Keeley, P. W. (2015). Design principles and developmental mechanisms underlying retinal mosaics. Biol. Rev. Camb. Philos. Soc. 90:854. doi: $10.1111 /$ brv.12139

Reichenbach, A., and Bringmann, A. (2013). New functions of Müller cells. Glia 61, 651-678. doi: 10.1002/glia.22477

Reichenbach, A., and Bringmann, A. (2016). Role of Purines in Müller Glia. J. Ocul. Pharmacol. Ther. 32, 518-533. doi: 10.1089/jop.2016.0131

Reichenbach, A., and Reichelt, W. (1986). Postnatal development of radial glial (Müller) cells of the rabbit retina. Neurosci. Lett. 71, 125-130. doi: 10.1016/ 0304-3940(86)90545-8

Ribot, J., Breton, R., Calvo, C.-F., Moulard, J., Ezan, P., Zapata, J., et al. (2021). Astrocytes close the mouse critical period for visual plasticity. Science 373, 77-81. doi: 10.1126/science.abf5273

Rich, K. A., Figueroa, S. L., Zhan, Y., and Blanks, J. C. (1995). Effects of Müller cell disruption on mouse photoreceptor cell development. Exp. Eye Res. 61, 235-248. doi: 10.1016/s0014-4835(05)80043-0

Richier, B., Vijandi, C., Mackensen, S., and Salecker, I. (2017). Lapsyn controls branch extension and positioning of astrocyte-like glia in the Drosophila optic lobe. Nat. Commun. 8, 1-17. doi: 10.1038/s41467-017-00384-z

Rillich, K., Gentsch, J., Reichenbach, A., Bringmann, A., and Weick, M. (2009). Light stimulation evokes two different calcium responses in Müller glial cells of the guinea pig retina. Eur. J. Neurosci. 29, 1165-1176. doi: 10.1111/j.1460-9568. 2009.06682.x

Rosa, J. M., Bos, R., Sack, G. S., Fortuny, C., Agarwal, A., Bergles, D. E., et al. (2015). Neuron-glia signaling in developing retina mediated by neurotransmitter spillover. Elife 4, 1-20. doi: 10.7554/eLife.09590

Ruzafa, N., Pereiro, X., Lepper, M. F., Hauck, S. M., and Vecino, E. (2018). A Proteomics Approach to Identify Candidate Proteins Secreted by Müller Glia that Protect Ganglion Cells in the Retina. Proteomics 18:1700321. doi: 10.1002/ pmic. 201700321

Saint-Geniez, M., Maharaj, A. S. R., Walshe, T. E., Tucker, B. A., Sekiyama, E., Kurihara, T., et al. (2008). Endogenous VEGF Is Required for Visual Function: Evidence for a Survival Role on Müller Cells and Photoreceptors. PLoS One 3:e3554. doi: 10.1371/journal.pone.0003554

Sardar Pasha, S. P. B., Münch, R., Schäfer, P., Oertel, P., Sykes, A. M., Zhu, Y., et al. (2017). Retinal cell death dependent reactive proliferative gliosis in the mouse retina. Sci. Rep. 7, 1-16. doi: 10.1038/s41598-017-09743-8

Satow, T., Bae, S.-K., Inoue, T., Inoue, C., Miyoshi, G., Tomita, K., et al. (2001). The Basic Helix-Loop-Helix Gene hesr2 Promotes Gliogenesis in Mouse Retina. J. Neurosci. 21, 1265-1273. doi: 10.1523/JNEUROSCI.21-04-01265.2001

Scheer, N., Groth, A., Hans, S., and Campos-Ortega, J. A. (2001). An instructive function for Notch in promoting gliogenesis in the zebrafish retina. Development 128, 1099-1107. doi: 10.1242/dev.128.7.1099

Schell, M. J., Brady, R. O., Molliver, M. E., and Snyder, S. H. (1997). D-Serine as a Neuromodulator: Regional and Developmental Localizations in Rat Brain Glia Resemble NMDA Receptors. J Neurosci. 17, 1604-1615. doi: 10.1523/ JNEUROSCI.17-05-01604.1997

Scott, R. S., McMahon, E. J., Pop, S. M., Reap, E. A., Caricchio, R., Cohen, P. L., et al. (2001). Phagocytosis and clearance of apoptotic cells is mediated by MER. Nat. 411, 207-211. doi: 10.1038/35075603

Seitz, R., Hackl, S., Seibuchner, T., Tamm, E. R., and Ohlmann, A. (2010). Norrin Mediates Neuroprotective Effects on Retinal Ganglion Cells via Activation of the Wnt/ $\beta$-Catenin Signaling Pathway and the Induction of Neuroprotective Growth Factors in Müller Cells. J. Neurosci. 30, 5998-6010. doi: 10.1523/ JNEUROSCI.0730-10.2010

Shekhar, K., and Sanes, J. R. (2021). Generating and Using Transcriptomically Based Retinal Cell Atlases. Annu. Rev. Vis. Sci. 7, 43-72. doi: 10.1146/annurevvision-032621

Shekhar, K., Lapan, S. W., Whitney, I. E., Tran, N. M., Macosko, E. Z., Kowalczyk, M., et al. (2016). Comprehensive Classification of Retinal Bipolar Neurons by Single-Cell Transcriptomics. Cell 166, 1308.e-1323.e. doi: 10.1016/j.cell.2016. 07.054

Stone, J., Itin, A., Alon, T., Pe’er, J., Gnessin, H., Chan-Ling, T., et al. (1995). Development of Retinal Vasculature Is Mediated by Hypoxia-Induced Vascular Endothelial Growth Factor (VEGF) Expression by Neuroglia. J. Neurosci. 15, 4738-4747. doi: 10.1523/JNEUROSCI.15-07-04738.1995

Stork, T., Sheehan, A., Tasdemir-Yilmaz, O. E., and Freeman, M. R. (2014). Neuron-Glia Interactions through the Heartless FGF Receptor Signaling Pathway Mediate Morphogenesis of Drosophila Astrocytes. Neuron 83, 388403. doi: 10.1016/j.neuron.2014.06.026

Taguchi, M., Shinozaki, Y., Kashiwagi, K., Shigetomi, E., Robaye, B., and Koizumi, S. (2016). Müller cell-mediated neurite outgrowth of the retinal ganglion cells via P2Y6 receptor signals. J. Neurochem. 136, 741-751. doi: 10.1111/jnc.13427

Tan, C. X., Burrus Lane, C. J., and Eroglu, C. (2021). Role of astrocytes in synapse formation and maturation. Curr. Top. Dev. Biol. 142, 371-407. doi: 10.1016/bs. ctdb.2020.12.010

Taylor, S., Srinivasan, B., Wordinger, R. J., and Roque, R. S. (2003). Glutamate stimulates neurotrophin expression in cultured Müller cells. Mol. Brain Res. 111, 189-197. doi: 10.1016/s0169-328x(03)00030-5

Todd, L., Squires, N., Suarez, L., and Fischer, A. J. (2016). Jak/Stat signaling regulates the proliferation and neurogenic potential of Müller glia-derived progenitor cells in the avian retina. Sci. Rep. 6, 1-16. doi: 10.1038/srep 35703

Toerne, C., von Menzler, J., Ly, A., Senninger, N., Ueffing, M., and Hauck, S. M. (2014). Identification of a Novel Neurotrophic Factor from Primary Retinal Müller Cells Using Stable Isotope Labeling by Amino Acids in Cell Culture (SILAC). Mol. Cell. Proteomics 13:2371. doi: 10.1074/mcp.M113.033613

Too, L. K., and Simunovic, M. P. (2021). Retinal Stem/Progenitor Cells Derived From Adult Müller Glia for the Treatment of Retinal Degeneration. Front. Cell Dev. Biol. 0:2683. doi: 10.3389/fcell.2021.749131

Raju, T. R., and Bennett, M. R. (1986). Retinal ganglion cell survival requirements: a major but transient dependence on Müller glia during development. Brain Res. 383, 165-176. doi: 10.1016/0006-8993(86)90017-x

Tran, M. D., and Neary, J. T. (2006). Purinergic signaling induces thrombospondin-1 expression in astrocytes. Proc. Natl. Acad. Sci. 103, 9321-9326. doi: 10.1073/pnas.0603146103 
Tremblay, M., Fugère, V., Tsui, J., Schohl, A., Tavakoli, A., Travençolo, B. A. N., et al. (2009). Regulation of Radial Glial Motility by Visual Experience. J. Neurosci. 29:14066. doi: 10.1523/JNEUROSCI.3542-09.2009

Tworig, J. M., Coate, C., and Feller, M. B. (2021). Excitatory neurotransmission activates compartmentalized calcium transients in Müller glia without affecting lateral process motility. Elife 2021:73202. doi: 10.7554/eLife.73202

Uckermann, O., Vargová, L., Ulbricht, E., Klaus, C., Weick, M., Rillich, K., et al. (2004). Glutamate-evoked alterations of glial and neuronal cell morphology in the guinea pig retina. J. Neurosci. 24, 10149-10158. doi: 10.1523/JNEUROSCI. 3203-04.2004

Ueki, Y., and Reh, T. A. (2013). EGF Stimulates Müller Glial Proliferation via a BMP Dependent Mechanism. Glia 61:778. doi: 10.1002/glia.22472

Ueki, Y., Wilken, M. S., Cox, K. E., Chipman, L. B., Bermingham-McDonogh, O., and Reh, T. A. (2015). A transient wave of BMP signaling in the retina is necessary for Müller glial differentiation. Development 142:533. doi: 10.1242/ dev.118745

Ueno, K., Iwagawa, T., Ochiai, G., Koso, H., Nakauchi, H., Nagasaki, M., et al. (2017). Analysis of Müller glia specific genes and their histone modification using Hes1-promoter driven EGFP expressing mouse. Sci. Rep. 7:3578.

Unterlauft, J. D., Claudepierre, T., Schmidt, M., Müller, K., Yafai, Y., Wiedemann, P., et al. (2014). Enhanced survival of retinal ganglion cells is mediated by Müller glial cell-derived PEDF. Exp. Eye Res. 127, 206-214. doi: 10.1016/j.exer. 2014.08.004

Uribe, R. A., and Gross, J. M. (2010). Id2a influences neuron and glia formation in the zebrafish retina by modulating retinoblast cell cycle kinetics. Development 137, 3763-3774. doi: 10.1242/dev.050484

Vincent, A. J., Lau, P. W., and Roskams, A. J. (2008). SPARC is expressed by macroglia and microglia in the developing and mature nervous system. Dev. Dyn. 237, 1449-1462. doi: 10.1002/dvdy.21495

Wang, J., O'Sullivan, M. L., Mukherjee, D., Puñal, V. M., Farsiu, S., and Kay, J. N. (2017). Anatomy and spatial organization of Müller glia in mouse retina. J. Comp. Neurol. 525, 1759-1777. doi: 10.1002/cne.24153

Wang, M., Ma, W., Zhao, L., Fariss, R. N., and Wong, W. T. (2011). Adaptive Müller cell responses to microglial activation mediate neuroprotection and coordinate inflammation in the retina. J. Neuroinflamm. 8, 1-19. doi: 10.1186/ 1742-2094-8-173

Wang, Y. P., Dakubo, G., Howley, P., Campsall, K. D., Mazarolle, C. J., Shiga, S. A., et al. (2002). Development of normal retinal organization depends on Sonic hedgehog signaling from ganglion cells. Nat. Neurosci. 5, 831-832. doi: $10.1038 / \mathrm{nn} 911$

Williams, P. R., Suzuki, S. C., Yoshimatsu, T., Lawrence, O. T., Waldron, S. J., Parsons, M. J., et al. (2010). In vivo development of outer retinal synapses in the absence of glial contact. J. Neurosci. 30, 11951-11961. doi: 10.1523/ JNEUROSCI.3391-10.2010

Williams, S. M., Diaz, C. M., Macnab, L. T., Sullivan, R. K. P., and Pow, D. V. (2006), Immunocytochemical analysis of $\mathrm{D}$-serine distribution in the mammalian brain reveals novel anatomical compartmentalizations in glia and neurons. Glia 53, 401-411. doi: 10.1002/glia.20300

Wohl, S. G., Jorstad, N. L., Levine, E. M., and Reh, T. A. (2017). Müller glial microRNAs are required for the maintenance of glial homeostasis and retinal architecture. Nat. Commun. 8, 1-15. doi: 10.1038/s41467-017-01624-y

Wohl, S. G., Reh, T. A., Christenson, L. K., Jimenez, D. F., and Digicaylioglu, M. (2016). The microRNA expression profile of mouse Müller glia in vivo and in vitro. Sci. Rep. 6:35423.

Wong, L. L., and Rapaport, D. H. (2009). Defining retinal progenitor cell competence in Xenopus laevis by clonal analysis. Development 136, 1707-1715. doi: $10.1242 /$ dev. 027607
Wurm, A., Pannicke, T., Iandiev, I., Wiedemann, P., Reichenbach, A., and Bringmann, A. (2006). The developmental expression of $\mathrm{K}+$ channels in retinal glial cells is associated with a decrease of osmotic cell swelling. Glia 54, 411-423. doi: 10.1002/glia.20391

Xie, H., Pallero, M. A., Gupta, K., Chang, P., Ware, M. F., Witke, W., et al. (1998). EGF receptor regulation of cell motility: EGF induces disassembly of focal adhesions independently of the motility-associated PLC $\gamma$ signaling pathway. J. Cell Sci. 111, 615-624. doi: 10.1242/jcs.111.5.615

Xu, H. P., Burbridge, T. J., Ye, M., Chen, M., Ge, X., Zhou, Z. J., et al. (2016). Retinal Wave Patterns Are Governed by Mutual Excitation among Starburst Amacrine Cells and Drive the Refinement and Maintenance of Visual Circuits. J. Neurosci. 36, 3871-3886. doi: 10.1523/JNEUROSCI.3549-15.2016

Xu, Q., Wang, Y., Dabdoub, A., Smallwood, P. M., Williams, J., Woods, C., et al. (2004). Vascular Development in the Retina and Inner Ear: Control by Norrin and Frizzled-4, a High-Affinity Ligand-Receptor Pair. Cell 116, 883-895. doi: 10.1016/s0092-8674(04)00216-8

Yamagata, M., Yan, W., and Sanes, J. R. (2021). A cell atlas of the chick retina based on single-cell transcriptomics. Elife 10, 1-39. doi: 10.7554/eLife.63907

Yan, W., Peng, Y.-R., van Zyl, T., Regev, A., Shekhar, K., Juric, D., et al. (2020). Cell Atlas of The Human Fovea and Peripheral Retina. Sci. Rep. 10, 1-17. doi: 10.1038/s41598-020-66092-9

Ye, X., Wang, Y., Cahill, H., Yu, M., Badea, T. C., Smallwood, P. M., et al. (2009). Norrin, Frizzled-4, and Lrp5 Signaling in Endothelial Cells Controls a Genetic Program for Retinal Vascularization. Cell 139, 285-298. doi: 10.1016/j.cell.2009. 07.047

Yoshida, S., Sotozono, C., Ikeda, T., and Kinoshita, S. (2001). Interleukin-6 (IL6) production by cytokine-stimulated human Müller cells. Curr. Eye Res. 22, 341-347. doi: 10.1076/ceyr.22.5.341.5498

Young, R. W. (1985). Cell differentiation in the retina of the mouse. Anat. Rec. 212, 199-205.

Zhang, J., Taylor, R. J., La Torre, A., Wilken, M. S., Cox, K. E., Reh, T. A., et al. (2015). Ezh2 maintains retinal progenitor proliferation, transcriptional integrity, and the timing of late differentiation. Dev. Biol. 403, 128-138. doi: 10.1016/j.ydbio.2015.05.010

Zhang, R. W., Du, W. J., Prober, D. A., and Du, J. L. (2019). Müller Glial Cells Participate in Retinal Waves via Glutamate Transporters and AMPA Receptors. Cell Rep. 27, 2871.e-2880.e. doi: 10.1016/j.celrep.2019.05.011

Zheng-Zheng, B., and Cepko, C. L. (1997). The expression and function of Notch pathway genes in the developing rat eye. J. Neurosci. 17, 1425-1434. doi: 10. 1523/JNEUROSCI.17-04-01425.1997

Conflict of Interest: The authors declare that the research was conducted in the absence of any commercial or financial relationships that could be construed as a potential conflict of interest.

Publisher's Note: All claims expressed in this article are solely those of the authors and do not necessarily represent those of their affiliated organizations, or those of the publisher, the editors and the reviewers. Any product that may be evaluated in this article, or claim that may be made by its manufacturer, is not guaranteed or endorsed by the publisher.

Copyright (c) 2022 Tworig and Feller. This is an open-access article distributed under the terms of the Creative Commons Attribution License (CC BY). The use, distribution or reproduction in other forums is permitted, provided the original author(s) and the copyright owner(s) are credited and that the original publication in this journal is cited, in accordance with accepted academic practice. No use, distribution or reproduction is permitted which does not comply with these terms. 